Revista de Estudios Histórico-Jurídicos

[Sección historia del derecho europeo]

XLII (Valparaíso, Chile, 2020)

[pp. 289-317]

\title{
El REFlejo del ideario jurídico-político de Alfonso X de Castilla EN SU PROYeCto legislativo
}

\author{
[Alfonso X of Castile's legal-political ideology reflected \\ In his legislative project]
}

\author{
Jesús García Díaz* \\ Universidad de Sevilla, España
}

\begin{abstract}
RESUMEN
El presente trabajo analiza la influencia de la concepción jurídico-política de Alfonso X de Castilla en la génesis y evolución de su proyecto legislativo. Desde un planteamiento diacrónico que considera la interacción de las circunstancias históricas del reinado, se examinan las razones de política legislativa presentes en la actuación del monarca en materia jurídica. Se ofrece de esta forma una nueva interpretación, holística y dinámica, del programa normativo ideado por Alfonso X.
\end{abstract}

Palabras clave

Alfonso X de Castilla - obra legislativa - ideario jurídico-político.

\section{AbSTRACT}

This article analyses the influence of Alfonso X of Castile's legal-political conception on his legislative project genesis and evolution. From a diachronic approach that considers the interaction of the historical circumstances of the reign, the reasons for the legislative politics -present in the actions taken by the monarch in legal matters-are examined. Hence, a new, holistic and dynamic interpretation is provided regarding the regulatory program conceived by Alfonso X.

\section{Key Words}

Alfonso X of Castile - legislative work - legal-political ideology.

RECiBido el 29 de abril de 2020 y ACEPTADO el 31 de mayo de 2020

Los estudios que han venido reflexionando sobre la importancia que desde los siglos XII-XIII en adelante tuvo la difusión del derecho común son tan profusos como solventes ${ }^{1}$. Aunque la recepción de esta nueva y vasta cultura jurídica en

* Doctor en Historia Medieval. Profesor del Departamento de Historia Medieval y Ciencias y Técnicas Historiográficas, Facultad de Geografía e Historia, Universidad de Sevilla. C/ Doña María de Padilla, s/n, 41004, Sevilla (España). Correo electrónico: jesusgd@us.es

${ }^{1}$ La historiografía preocupada por este tema es desbordante, algunos ejemplos paradigmáticos, sin pretender ser exhaustivos, en Calasso, Francesco, Medio Evo del diritto (Milano, 1954), pp. 75 ss.; KorschaKer, Paul, Europa y el derecho romano (Madrid, 1955), pp. 33 ss.; GarCía-Gallo DE DIEGo, Alfonso, Cuestiones de historiografía jurídica, II. La historia del derecho europeo, en AHDE., 44 (1974), pp. 751-764; CARPINTERo BeníteZ, Francisco, Mos italicus, mos gallicus y el humanismo racionalista. Una contribución a la historia de la metodología jurídica, en Ius Commune, 6 (1977), pp. 108-171; CAVANNA, Adriano, Storia del diritto moderno en Europa, I: Le fonti e il 
las distintas regiones de Europa no revistió de un carácter uniforme ni tuvo la misma secuencia sincrónica, se trata de un fenómeno general a todo el Occidente medieval y, como tal, los reinos hispano-cristianos no fueron ajenos al mismo ${ }^{2}$.

En el caso concreto de la Corona de Castilla, la obra legislativa auspiciada por el monarca Alfonso X el Sabio ha sido tradicionalmente considerada como el primer y mejor exponente del inicio de la penetración del derecho común. En efecto, la redacción de los principales textos jurídicos salidos del scriptorium alfonsí inaugura, de forma nítida tras tímidos avances anteriores, la llegada del ius commune a estos reinos. Así, desde la propia institución monárquica y bajo el directo patronazgo regio, se dan los primeros pasos de la recepción de un derecho de inspiración romano-canónica que comenzaba a circular y difundirse por buena parte de Europa ${ }^{3}$. Precisamente por ello, el proyecto legislativo promovido por

pensiero giuridico (Milano, 1973), pp. 49 ss.; PÉREz MARTín, Antonio (coord.), España y Europa: un pasado jurídico común (Murcia, 1986), pp. 11 ss.; BraVo LiRA, Bernardino, El derecho indiano y sus raices europeas: derecho común y propio de Castilla, en AHDE., 58 (1988), pp. 5-80; CORTESE, Ennio, Il rinascimiento giuridico medievale (Roma, 1996), pp. 29 ss.; BERMAN, Harold Joseph, La formación de la tradición jurídica de Occidente (México, 1996), pp. 97 ss.; IGLESIA FERREIRÓs, Aquilino (ed.), Tercer Simposi Internacional del Dret Comú $i$ Catalunya: ius propium-ius commune a Europa (Barcelona, 1993), pp. 17 ss.; LALINDE ABADía, Jesús, El modelo jurídico europeo del siglo XIII, en Glossae: Revista de Historia del Derecho Europeo, 5-6 (1993-1994), pp. 17-34; CORTESE, Ennio, Il diritto nella storia medievale. II. Il baso medioevo (Roma, 1995), pp. 25 ss.; CoING, Helmut, Derecho privado y europeo, I: Derecho común más antiguo (Madrid, 1996), pp. 69 ss.; Grossi, Paolo, El orden jurídico medieval (Madrid, 1996), pp. 225-232; IgLEsia Ferreirós, Aquilino, La forja de la civilización europea: el ius commune, en GARCía Marín, José María (dir.), Cultura jurídica europea: una herencia persistente (Sevilla, 2001), pp. 39-60; HESPANHA, António Manuel; Serrano GonzÁlez, Antonio (eds.), Cultura jurídica europea: síntesis de un milenio (Madrid, 2002), pp. 43 ss.; Clavero SALVADOR, Bartolomé, Temas de historia del derecho: derecho común (Salamanca, 2008), pp. 11-29; MONTANOS FERRÍn Emma, Experiencias de derecho común europeo: siglos XII-XVII (Santiago de Compostela, 2010), pp. 29 ss.

${ }^{2}$ Entre otros García y García, Antonio, La penetración del derecho clásico en España, en AHDE., 36 (1966), pp. 575-592; FONT RIUs, Josep María, La recepción del derecho romano en la Península Ibérica durante la Edad Media (Montpellier, 1967), pp. 13 ss.; BARrero GARCíA, Ana María, El derecho romano en los Furs de Valencia de Jaime I, en AHDE., 41 (1971), pp. 639-664; Braga Da Cruz, Guilherme, O direito sudsidiário na História do direito português, en Revista Portuguesa de História, 14 (1975), pp. 177-316; Iglesias Ferreirós, Aquilino, La creación del derecho en Cataluña, en AHDE., 47 (1977), pp. 99-123; ÉL MISMO, ¿El primer testimonio de la recepción del derecho romano en Cataluña?, en Revista Jurídica de Cataluña, 79 (1978), pp. $277-$ 231; Lacarra y De Miguel, José María, En torno a la formación del Fuero General de Navarra, en $A H D E$., 50 (1980), pp. 93-110; MARTÍNEZ DíEZ, Gonzalo, Los comienzos de la recepción del derecho romano en España y el Fuero Real, en Diritto comune e diritti locali nella storia dell'Europa. Atti del Convegno di Varenna (Milano, 1980), pp. 259 ss.; Wolf, Armin, Los "Fori Aragonum" de 1247 y el "Vidal Mayor". Sus relaciones con la legislación europea, en AHDE., 53 (1983-1984), pp. 177-203; Pérez Martín, Antonio, España y Europa: un pasado jurídico común (Murcia, 1986), pp. 17 ss.; Él MISMO, El estudio de la recepción del derecho común en España, en SALVADOR Coderch, Pablo: Cerdá Ruiz-Funes, Joaquín (coords.), I Seminario de Historia del Derecho y derecho privado. Nuevas técnicas de investigación (Barcelona, 1985), pp. 241-325.

${ }^{3}$ Clavero Salvador, Bartolomé, Notas sobre el derecho territorial castellano (1367-1445), en Historia. Instituciones. Documentos, 3 (1976), p. 148; Martínez DíEZ, Gonzalo (ed.), Leyes de Alfonso X. II: Fuero Real (Ávila, 1988), pp. 56 ss.; Pérez de Tudela y Velasco, María Isabel, Ideario político y orden social en Las Partidas de Alfonso X, en En la España Medieval, 14 (1991), 
Alfonso X constituyó una realidad bien diferenciada de las circunstancias jurídicas secularmente acuñadas en sus reinos ${ }^{4}$, encontrándonos ante un programa normativo que desprende un hálito renovador, llegando a convertirse en un hito en la Historia del Derecho, no sólo castellano, sino hasta peninsular e incluso europeo 5 .

En concordancia con esta importancia, dentro de la prolija bibliografía sobre el reinado de Alfonso $\mathrm{X}^{6}$, aquellos trabajos preocupados por analizar e interpretar su trascendental obra legislativa constituyen uno de los capítulos más precoces y sobresalientes ${ }^{7}$. Pero, de la misma forma que elogiamos la ingente y rigurosa labor

pp. 183-200; Piña Homs, Román, Alfonso X el Sabio: Universalidad frente a localismo, en Alvarado Planas, Javier (coord.), Espacios y fueros en Castilla-La Mancha (Siglos XI-XVI). Una perspectiva metodológica (Madrid, 1995), pp. 471-486; GONZÁLEZ JiMÉNEZ, Manuel, Alfonso X el Sabio (Barcelona, 2004), pp. 373 ss.

${ }^{4}$ Pérez-Prendes y MuÑoz de Arracó, José Manuel, Las leyes de Alfonso el Sabio, en Revista de Occidente, 43 (1984), p. 64.

${ }^{5}$ Especialmente en lo que respecta a las Partidas, cuya influencia no sólo ha sido profunda en el derecho castellano, sino en el de otros reinos peninsulares. Un ejemplo en D'ABADAL I Vinyals, Ramón, Les Partidas a Catalunya durant l'Edat Mitjana, en Estudis Universitaris Catalans, 4 (1912), pp. 159-180. Otro aspecto sintomático de ello podemos encontrarlo en las tempranas traducciones de esta obra -o bien de partes de la misma- al portugués, catalán..., cfr. De Azevedo Ferreira, José Pedro, Alphonso X: Primeyra Partida (Braga, 1980), pp. 9 ss.; Iglesia Ferreirós, Aquilino, Una traducción catalana de la Segunda Partida, en Anuario de Estudios Medievales, 17 (1987), pp. 265-278. Asimismo, la influencia de las Partidas resulta evidente en el derecho indiano: Bravo LiRA, Bernardino, El derecho indiano y sus raíces europeas, cit (n. 1), pp. 5-80; ÉL MISMO, Derecho común y derecho propio en el Nuevo Mundo (Santiago de Chile, 1989), pp. 29 ss.; BARRIENTOS GRANDÓN, Javier, La cultura jurídica en la Nueva España (México, 1993), pp. 31 ss.; ÉL MISMO, El sistema del “ius commune" en las Indias occidentales, en Rivista Internazionale di Diritto Comune, 10 (1999), pp. 53-138; BERnAL GómEz, Beatriz, El derecho castellano dentro del sistema jurídico indiano, en Anuario Mexicano de Historia del Derecho, 10 (1998), pp. 89-105. De la misma forma la influencia de las Partidas se deja sentir en territorios de los actuales Estados Unidos, como Florida, que pertenecieron a los dominios de la Corona hispánica, cfr. O’Callaghan, Joseph F., El rey Sabio. El reinado de Alfonso X de Castilla (Sevilla, 1999), pp. 324-325; Procter, Evelyn S., Alfonso X de Castilla, patrono de las letras y del saber (Murcia, 2002), p. 63.

${ }^{6}$ Una pormenorizada recopilación bibliográfica referida a su figura y reinado en GONZÁLEZ Jiménez, Manuel, Alfonso Xel Sabio, cit. (n. 3), pp. 457 ss.

${ }^{7}$ La historiográfica sobre la obra legislativa de Alfonso X es ingente, algunas recopilaciones en Iglesia Ferreirós, Aquilino, Alfonso X, su labor legislativa y los historiadores, en Historia. Instituciones. Documentos, 9 (1982), pp. 2-112; GARCÍA-SADELL, Luis María, Bibliografía sobre la obra jurídica de Alfonso el Sabio y su época (1800-1985), en Revista de la Facultad de Derecho. Universidad Complutense, 9 (1985), pp. 287-319; CRADDOCK, Jerry R, The Legislative Works of Alfonso Xel Sabio: A Critical Bibliography. (London, 1986), pp. 9 ss.; SÁnCHEZ-ArCilla Bernal, José, La obra legislativa de Alfonso X el Sabio. Historia de una polémica, en Montoya Martínez, Jesús; Domínguez Rodríguez, Ana (coords.), El scriptorium alfonsí: de los libros de astrología a las Cantigas de Santa María (Madrid, 1999), pp. 17-81. Desde el año 1999 en adelante, y por tanto no recogidas en la última de las recopilaciones citadas, han aparecido nuevas aportaciones; podríamos destacar Pérez Martín, Antonio, Las Siete Partidas, obra cumbre del derecho común en España, en GARCÍA Y GARCÍA, Antonio et alii, El derecho común y Europa: Actas de las Jornadas Internacionales de Historia de El Escorial (Madrid, 2000), pp. 21-34; IgLESIA Ferreirós, Aquilino, Por que nos, don Alfonso, avemos poder de fazer leyes, en Alcanate: Revista de Estudios Alfonsies, 3 (2002-2003), pp. 55-92; SÁNCHEZ-ARCILLA BERnAL, José, La teoría de la ley en la obra legislativa de Alfonso Xel Sabio, en Alcanate: Revista de Estudios Alfonsies, 6 (2008-2009), pp. 81-123. 
historiográfica hasta ahora desarrollada, debemos constatar que no siempre ha facilitado la comprensión del proyecto normativo planificado por el monarca. De hecho, una parte significativa de esta reflexión histórico-jurídica se ha centrado en un enconado -y a veces poco enriquecedor- debate en torno a los más destacados textos jurídicos redactados bajo patrocinio alfonsi $i^{8}$. Y, como consecuencia de ello, tal polémica ha venido a redundar en un par de excesos substanciales.

En primer lugar, la discusión historiográfica sostenida se ha enfocado en ofrecer una precisa y exacta datación cronológica de los principales códigos legislativos atribuidos al monarca, esto es, Fuero Real, Espéculo y Partidas. Quizás desde una perspectiva excesivamente monolítica, distintos autores han debatido hasta la saciedad acerca del carácter y finalidad de cada una de tales obras, así como de su posible autoría y fecha de promulgación?.

En segunda instancia, eventualmente se ha incurrido en una disociación entre la actividad jurídica desplegada por Alfonso X y las propias circunstancias históricas de su reinado, vislumbrándose una imagen demasiado rígida de su obra legislativa. En este sentido pensamos que las decisiones llevadas a cabo por el monarca en el ámbito del derecho estuvieron influenciadas por los distintos acontecimientos políticos que le tocó vivir, y resulta evidente que estos últimos no fueron inmutables a lo largo de más de treinta años de reinado ${ }^{10}$.

Si se acepta esta interacción entre las circunstancias históricas y el paulatino desenvolvimiento del programa legislativo del monarca castellano, resulta evidente la existencia de un significado eminentemente político en toda su obra jurídica. Aparece de esta forma un nuevo perfil de la actuación de Alfonso X en el ámbito del derecho, pues en sus decisiones en materia jurídica se manifiestan también razones de política legislativa ${ }^{11}$. Esta trascendental faceta de la actuación del

${ }^{8}$ Un buen resumen en Sánchez-Arcilla Bernal, José, La obra legislativa de Alfonso X el Sabio. Historia de una polémica, cit (n. 7), pp. 17-81.

${ }^{9}$ Se ha discutido muchísimo, especialmente la autoría y cronología, de las obras atribuidas a Alfonso X. Aunque probablemente simplifiquemos en exceso, podemos decir que en su día García-Gallo expresó unas opiniones que gozaron de mucho predicamento, $c f r$. GARCía-GALLO De Diego, Alfonso, Nuevas observaciones sobre la obra legislativa de Alfonso X, en AHDE., 46 (1976), pp. 609-670. No obstante, y debido a las críticas que tales ideas comenzaban a recibir, los posicionamientos iniciales fueron parcialmente modificados por el autor, $c f r$. GARCía-GALLO De Diego, Alfonso, La obra legislativa de Alfonso X. Hechos e hipótesis, en AHDE., 54 (1984), pp. 97-162; ÉL MISMO, La problemática de la obra legislativa de Alfonso X, en Boletín del Ilustre colegio de Abogados de Madrid, 5 (1984), pp. 8-19. A pesar de esta alteración en algunos de sus postulados, la interpretación de García-Gallo fue criticada por CRADDOCK, Jerry R., La cronología de las obras legislativas de Alfonso X el Sabio, en AHDE., 54 (1981), pp. 365-418, así como por Iglesia Ferreirós, Aquilino, Alfonso X y su obra legislativa: algunas reflexiones, en $A H D E ., 50$ (1980), pp. 531-562; Él MISMO, Fuero Real y Espéculo, en AHDE., 52 (1982), pp. 111-191; Él mismo, La labor legislativa de Alfonso X el Sabio, en Pérez Martín, Antonio (ed.), España y Europa, un pasado jurídico común, cit. (n. 1), pp. 275-599.

${ }^{10}$ Pérez Martín, Antonio, Hacia un derecho común europeo: la obra jurídica de Alfonso X, en Rodríguez Llopis, Manuel (coord.), Alfonso X. Aportaciones de un rey castellano a la construcción de Europa (Murcia, 1997), p. 119.

${ }^{11}$ Iglesia Ferreirós, Aquilino, La labor legislativa de Alfonso X, cit. (n. 9), p. 292; Barragán, Guillermo C., La obra legislativa de Alfonso el Sabio (Buenos Aires, 1983), p. 28. 
monarca en el campo normativo se encuentra íntimamente ligada a su particular noción del poder real y del propio derecho. Parece pues procedente, teniendo en cuenta tales condicionantes, analizar cómo el ideario jurídico-político de Alfonso $\mathrm{X}$ influyó en la génesis y evolución de su proyecto legislativo.

\section{REIVINDICACIÓN DEL MONOPOLIO REGIO EN LA CREACIÓN DE DERECHO}

La reivindicación de la capacidad de creación de derecho por parte del monarca constituye el punto de partida ineludible del renovador programa normativo auspiciado por Alfonso X. No en vano, se trata esta de una reclamación desde la cual se articulará gran parte de su concepción jurídico-política y que, a la postre, terminará dando sentido a muchas de las decisiones y medidas llevabas a cabo por el rey en materia legislativa ${ }^{12}$.

Esta remozada reivindicación de la capacidad regia para promulgar leyes no sólo va a determinar la construcción de buena parte de la obra jurídica alfonsí, sino que representa asimismo una de las primeras evidencias del inicio de la recepción del derecho común ${ }^{13}$. Como es sobradamente conocido, la recuperación por parte del rey de la plenitudo potestatis se identifica con un principio jurídico de clara concepción romanista. De forma que, al igual que sucede en otras monarquías europeas ${ }^{14}$, también para el caso castellano podemos verificar que son los materiales insertos en el nuevo ius commune-particularmente en el derecho justinianeo- los que le van a proporcionar a Alfonso X el armazón doctrinal sobre el que edificar la reivindicación de la potestad normativa regia ${ }^{15}$.

En efecto, parte del nuevo pensamiento jurídico dominante en la Europa del momento se muestra plenamente en sintonía con lo que Alfonso X pensaba acerca de sus propias competencias en esta materia y de la institución que él mismo representa, entre las cuales aparece, en un primerísimo plano, la de fazer leyes $^{16}$. Así queda claramente reflejado en los principales códigos redactados bajo patrocinio del monarca, en los que se deja claro que: "ninguno non puedeffazer leys ssinon enperador o rrey u otro por ssu mandamiento dellos; e ssi otros la ffezieren ssin ssu mandado non deven aver nonbre leyes nin deven seer obedeçidas nin guardadas

\footnotetext{
${ }^{12}$ Iglesia Ferreirós, Aquilino, Fuero Real y Espéculo, cit. (n. 9), p. 113; Él mismo, La labor legislativa de Alfonso X el Sabio, cit. (n. 9), pp. 292 ss.

${ }^{13}$ Según González Díez, esta prerrogativa regia se puso ya de manifiesto en tiempos de Fernando III, concretamente a partir de la concesión a la ciudad de Córdoba del Fuero de Toledo, cfr. GonzÁlez Díez, Emiliano, Del Fuero de la ciudad de Sevilla, en GonZÁlez Jiménez, Manuel (dir.), Sevilla 1248. Congreso Internacional Conmemorativo del 750 Aniversario de la conquista de la ciudad de Sevilla por Fernando III, rey de Castilla y León (Sevilla, 2000), p. 294.

${ }^{14}$ García Díaz, Jesús, La Europa de Alfonso X el Sabio. En torno a una historia jurídica comparada, en Alcanate: Revista de Estudios Alfonsies, 8 (2012-2013), pp. 267 ss.

${ }^{15}$ Vallejo Fernández De La Reguera, Jesús, Ruda equidad, ley consumada: Concepción de la potestad normativa, 1250-1350 (Madrid, 1992), pp. 64 ss.

${ }^{16}$ Iglesia Ferreirós, Aquilino, Por que nos, don Alfonso, avemos poder de fazer leyes, cit. (n. 7), pp. 55-92; ÉL mISmo, Derecho municipal y derecho territorial en la Corona de Castilla, en El Fuero de Santander y su época. Actas del Congreso Conmemorativo de su VIII Centenario (Santander, 1989), p. 120.
} 
por leys nin deven valer en ningún tiempo" ${ }^{17}$. Ahora bien, esta concepción sobre la plena capacidad del rey para crear leyes no puede ser contemplada en exclusividad desde el punto de vista positivo, pues la defensa del monopolio regio en materia de génesis normativa implicaba negar la validez de otras vías subsidiarias de creación judicial del derecho. En este sentido debemos recordar que, a mediados del siglo XIII, permanecía vigente en muchas zonas de la Corona de Castilla una gran tradición en cuanto a la libertad de creación del derecho se refiere. Tal es así que, de facto, esta efectiva reivindicación de un monopolio legislativo en manos del monarca venía a chocar abiertamente con viejas concepciones jurídicas de raigambre altomedieval, extrañas al nuevo derecho común, pero que gozaban de gran arraigo popular ${ }^{18}$.

Y decimos esto porque, ciertamente, la asunción por parte de Alfonso X de tal principio jurídico no sólo significaba la defensa de la capacidad del rey para crear leyes, sino también la negación de otras fuentes arbitrarias -tanto municipales como señoriales ${ }^{19}$ - para hacerlo. En otras palabras, esta reivindicación de un monopolio regio en el ámbito jurídico implicaba romper abiertamente con una larga tradición basada en sentencias o fazañas de tribunales ajenos al rey o, simplemente, en la costumbre no escrita ${ }^{20}$.

Este rompimiento se puede apreciar en los propios textos jurídicos salidos del scriptorium del rey Sabio, ya que: "por ffazer entender a los omes dessentendudos que nos, el ssobredicho rrey don Alffonso auemos poder de ffazer estas leyes tan bien commo los otros que las ffezieron ante de nos oy, mas querémoslo mostrar por todas estas maneras: por rrazón e por fazanna e por derecho. E por rrazón que ssi los enperadores e los rreys que los inperios e los rregnos ouieron por eleçión pudieron ffazer leys en aquello que touieron commo en comienda, quanto más nos, que auemos el rregno por derecho heredamiento. Porffazanna, ca non tan ssolamiente los rreys de Espanna que ffueron antiguamente las fezieron, mas condes e iuezes e adelantados que eran de menor guisa, e ffueron guardadas ffasta en este tienpo; e pues que éstos las ffezieron que avien mayores sobre ssý, mucho más las podemos nos ffazer que por la merçed de Dios non avemos mayor sobre nos en el tenporal. Por derecho, ca lo puedemos prouar por las leys rromanas e por derecho de Ssanta Eglesia e por las leys d'Espanna que ffezieron los godos en que dize en cada vna déstas que los enperadores e los rreys an poder de ffazer leyes e de anader en ellas e de minguar en ella e de camiar cada que mester ssea. Onde por todas estas rrazones auemos poder conplidamente de ffazer leyes" 21.

Íntimamente ligada a esta reclamación de una exclusividad legislativa en manos del monarca, debemos traer a colación otro principio de no menor importancia

${ }^{17}$ Espéculo, Libro Primero, Título I, Ley III. Igualmente queda reflejado en las Partidas: "Enperador o Rey puede fazer leyes sobre las gentes de su sennorio e otro ninguno non ha poder de las fazer en lo temporal, fueras ende, si lo fiziese con otorgamiento dellos. E las que de otra manera fueren fechas, no han nonbre nin fuerça de leyes, ni deuen valer en ningún tiempo", cfr. Primera Partida, Título I, Ley XII.

${ }^{18}$ Como el caso del viejo principio "quod omnes tangit debet ab omnibus approbari".

${ }^{19}$ Iglesia Ferreirós, Aquilino, Derecho municipal, derecho señorial, derecho regio, en Historia. Instituciones. Documentos, 4 (1977), pp. 130 ss.

${ }^{20}$ Bermejo Cabrero, José Luis, Fazañas e historiografia, en Hispania, 32 (1972), pp. 61-76.

${ }^{21}$ Espéculo, Libro Primero, Título I, Ley XIII. 
dentro del ideario jurídico-político alfonsí, y sin el cual esa capacidad regia de creación de derecho podría quedar desvirtuada. Nos estamos refiriendo a una muy similar reivindicación del monopolio regio en la administración de justicia o, cuanto menos, a su creciente control por parte de la monarquía ${ }^{22}$.

A este respecto lo primero que debemos tener presente es la existencia de evidentes conexiones entre ambos principios: la función real y la justicia cumplida, esa que "faze a los omes biuir cada vno como conuiene" 23 . Como es bien sabido, una de las principales imágenes del poder monárquico durante el periodo medieval es la del rey justo ${ }^{24}$, pudiendo constituir el caso castellano un buen ejemplo de ella ${ }^{25}$. De esta forma, y desde una fecha relativamente temprana, ya se vislumbra entre los principios jurisprudenciales imperantes una creciente identificación entre las funciones propias de un buen rey y el hecho de impartir justicia, esto es, "dar a cada uno lo suyo" o "departir e dar a cada vno su derecho según su estado, assí commo meresçe e le conuiene" ${ }^{26}$. Se trata esta además de un tipo de concepción con un enorme porvenir, haciéndose más evidente a medida que nos adentramos en los siglos finales de la Edad Media ${ }^{27}$.

Precisamente por ello, poco ha de sorprendernos que un monarca como Alfonso X considerase el control de la administración judicial un pilar fundamental dentro su concepción jurídico-política y, consecuentemente, uno de los hitos imprescindibles a la hora de intentar materializar su proyecto legislativo. Veamos en este caso lo que dice el Fuero Real, un texto que la mayor parte de la historiografía considera una obra de principios de su reinado, y donde se producen

${ }^{22}$ GonzÁlez Jiménez, Manuel, Alfonso X, rey de Castilla y León (1252-1284), en Montoya Martínez, Jesús; Domínguez Rodríguez, Ana (dirs.), El scriptorium alfonsí, cit. (n. 7), p. 4.

23 "e al gouernamiento de las gentes pertenesçen las leyes que ayuntan los coraçones de los omes por amor: e esto es, derecho e razón: ca destas dos sale la justicia cunplida, que faze a los omes biuir cada vno como conuiene”, cfr. Primera Partida, Título I, Ley VII. Véase también PÉREZ DE LA CANAL, Miguel Ángel, La justicia en la corte de Castilla durante los siglos XIII al XIV, en Historia. Instituciones. Documentos, 2 (1975), pp. 385-471; MADERo EGUÍA, Marta, Formas de la justicia en la obra jurídica de Alfonso X el Sabio, en Hispania, 66/2 (1996), pp. 447-466; KLEINE, Marina, Os elementos do corpo politico e a justiça nas Siete Partidas de Alfonso X (1221-1284), en Politeia: Hist. e Soc., 5/1 (2005), pp. 103-118.

${ }^{24}$ MarongiU, Antonio, Un momento típico de la monarquía medieval: el rey juez, en $A H D E$., 23 (1953), pp. 677-715; NiETO SORIA, José Manuel, Fundamentos ideológicos del poder real en Castilla, siglos XIII-XVI (Madrid, 1988), pp. 159 ss.; PéreZ-Prendes y MuÑoz de Arracó, José Manuel, Facer justicia, en Moneda y Crédito, 129 (1974), pp. 17-90; Bermejo Cabrero, José Luis, Principios y apotegmas sobre la ley y el rey en la Baja Edad Media castellana, en Hispania, 129 (1975), pp. 31-47; Ullmann, Walter, Principios de gobierno y política en la Edad Media (Barcelona, 1992), pp. 125 ss.; KanTOROwicz, Ernst, H., Los dos cuerpos del rey. Un estudio de teología política medieval (Madrid, 2012), pp. 115 ss.

${ }^{25}$ Vallejo Fernández de la Reguera, Jesús, Ruda equidad, ley consumada, cit. (n. 15), pp. 177-180; Él mismo, Relectura del Fuero Real, en Romano, Andrea (a cura di), Federico II legislatore del Regno di Sicilia nell'Europa del Duecento. Per una storia comparata delle codificazioni europee (Roma, 1997), p. 500.

${ }^{26}$ Segunda Partida, Título V, Ley VIII.

${ }^{27}$ SuÁrez Bilbao, Fernando; Navalpotro y SÁnchez-Peinado, Jesús María, La consolidación del derecho común en Castilla. La obra legislativa de los Reyes Católicos, en Le droit commun et l'Europe. Journées Internationales d'Histoire du Droit de L'Escurial (Madrid, 2000), p. 287. 
los primeros pasos en la tentativa de controlar la administración de justicia. Así, en aquellos concejos a los que Alfonso X concede esta normativa, de ahora en adelante sólo podrán juzgar los alcaldes designados por el monarca: "ningún omne non sea osado de iudgar pleytos, si non fuere alcalde puesto por el rey, o si non fuere por plazer de las partidas que lo tomen por aueniençia pora iudgar algún pleyto [...] e los alcaldes que fueren puestos por el rey non metan otros en su lugar que iudguen, si non fueren dolientes o flacos de guisa que non pueden iudgar" 28 .

De hecho, existe una interesantísima relación entre las distintas concesiones del Fuero Real y la designación de alcaldes del rey en esos mismos concejos a los que esta nueva normativa municipal le es ahora otorgada ${ }^{29}$. No en vano, esta conexión entre la introducción del Fuero Real y la designación de alcaldes reales constituye el inicio de un proceso de creciente intervencionismo monárquico en el control del gobierno municipal. Una intromisión que, no por casualidad, donde se va a materializar más tempranamente va a ser en aquellos cargos concejiles directamente relacionados con la administración de justicia ${ }^{30}$. En esta misma línea, tampoco resulta baladí que precisamente fuese en los “jóvenes" concejos de las tierras recientemente incorporadas a la Corona, esto es, en los gobiernos municipales de la Baja Andalucía y de Murcia, donde Alfonso X decidiese hacer efectivo, por primera vez, una designación directa de aportellados ${ }^{31}$. A este respecto parece indudable, sobre todo si tenemos en cuenta el rechazo que esta práctica ocasionó en otras zonas de Castilla y su éxito en muchos concejos andaluces, que la ausencia de tradición normativa en los territorios últimamente conquistados y colonizados facilitó que la monarquía pudiese dar importantes pasos en este sentido ${ }^{32}$.

${ }^{28}$ Fuero Real, Libro I, Título VII. Véase también, del mismo Libro y Título, la Ley IV: "todos los pleytos que acahecieren tan bien de iusticia como de otras cosas, iúdguenlos los alcaldes que fueren puestos por el rey e los que pusieren los alcaldes en su lugar assi commo manda la ley".

${ }^{29}$ GonZÁlez Jiménez, Manuel, Sobre fueros, concejos y politica municipal de Alfonso X, en Actas del II Congreso de Historia de Albacete. II: Edad Media (Albacete, 2002), pp. 14-15; ÉL mismo, La creación del derecho local y territorial andaluz. De Alfonso $X$ a los Reyes Católicos, en Initium. Revista Catalana d'Història del Dret, 9 (2004), pp. 132-134.

${ }^{30}$ GonZAlez JimÉnez, Manuel, Alfonso X y las oligarquías urbanas de caballeros, en Glossae. Revista de Historia del Derecho Europeo, 5-6 (1993-1994), pp. 195-214.

${ }^{31}$ V.gr. el caso de Alicante, a cuyo concejo Alfonso X concede el Fuero de Córdoba y las franquezas de Cartagena, reservándose sin embargo el nombramiento de juez, alcaldes y demás aportellados, cfr. TORRES FonTES, Juan, Fueros y privilegios de Alfonso X al reino de Murcia (Murcia, 1973) Doc. $n^{\circ}$. XIII, pp. 16-20. O el más evidente de Sevilla, cuyo concejo se organiza entre 1252 y 1253 , y donde el rey nombró directamente a todos los alcaldes, a quienes desde entonces se les denomina "alcaldes del rey y de Sevilla", cfr. GonZALEZ ArCE, José Damián, Cuadernos de ordenanzas y otros documentos sevillanos de Alfonso X, en Historia. Instituciones. Documentos, 16 (1989), pp. 103-132; Kirschberg SChenck, Deborah; Fernandez Gómez, Marcos, El Concejo de Sevilla en la Edad Media (1248-1454). Organización institucional y fuentes documentales (Sevilla, 2002), pp. 263 ss.

${ }^{32}$ Estos primeros pasos en la designación de miembros de los concejos andaluces -hacia lo que será ya en el reinado de Alfonso XI el sistema de regimiento- ha sido ampliamente corroborado en el trabajo sobre la organización institucional del concejo hispalense de KIRSCHBERG SCHENCK, Deborah; Fernández Gómez, Marcos, El Concejo de Sevilla en la Edad Media, cit. (n. 31), pp. 21-72. No obstante, esta realidad ya había sido intuida por Borrero FernándEZ, Mercedes, El Concejo de Sevilla, en González Jiménez, Manuel; Borrero Fernández, Mercedes; Montes 
En cualquier caso, resulta indudable que esta actuación de Alfonso X en lo que a nombramientos de cargos concejiles relacionados con la administración de justicia se refiere fue mucho más amplia en el espacio. Y es que la designación de alcaldes del rey se va a poner de manifiesto tanto fuera de las fronteras andaluzas y murcianas como más allá de los municipios a los que el Fuero Real les había sido concedido. Tal es así que este intervencionismo regio tendrá lugar, incluso, en municipios que ni siquiera contaban a la altura de mediados del siglo XIII con una normativa municipal de origen regio ${ }^{33}$.

Podemos pues constatar la presencia de alcaldes del rey en otros muchos municipios castellano-leoneses, indistintamente del modelo foral por el que estos se rigiesen ${ }^{34}$. En otras palabras, una gran cantidad de concejos de realengo fueron objeto, en mayor o menor medida, de un creciente intervencionismo por parte de Alfonso X a través del cual intentó llevar a la práctica, también en este espacio clave de la sociedad política del reino, un creciente control de la administración de justicia ${ }^{35}$.

En definitiva, nos encontramos ante el despliegue de una política regia con una doble finalidad: la reivindicación del monopolio legislativo por parte del monarca y un creciente control de la administración de justicia. Dos aspectos íntimamente relacionados entre sí y que, de acuerdo con el ideal jurídico-político de Alfonso $\mathrm{X}$, se convierten en estadios difícilmente prescindibles a la hora de intentar llevar a la práctica su proyecto legislativo.

\section{UNIFICACIÓN JURÍDICA DE SUS REINOS}

Junto a la reivindicación del monopolio regio en materia legislativa, otros dos aspectos completan el significado político de la obra promovida en este ámbito

Romero-Camacho, Isabel, Sevilla en tiempos de Alfonso Xel Sabio (Sevilla, 2000), pp. 97-155. A este respecto véase también GONZÁLEZ JiMÉNEZ, Manuel, Concejos y ciudades andaluzas: el gobierno urbano, en Concejos y ciudades en la Edad Media Hispánica: II Congreso de Estudios Medievales. (Ávila, 1990), pp. 239-260; Peinado Santaella, Rafael Gerardo, Las élites de poder en las ciudades de la Andalucía Bética, en Las ciudades andaluzas (siglos XIII-XVI). Actas del VI Coloquio Internacional de Historia Medieval de Andalucía (Málaga, 1991), pp. 337-356; CollaNTES DE Terán SÁnchez, Antonio, El concejo de Sevilla en la Edad Media, en Ayuntamiento de Sevilla. Historia y Patrimonio. (Sevilla, 1992), pp. 13-31; KIRSCHBERG SCHENCK, Deborah, La reforma municipal en Sevilla: oligarquía hispalense y la implantación del regimiento en 1286, en Archivo Hispalense, 237 (1995), pp. 11-40; Borrero FernándeZ, Mercedes, Sevilla en la segunda mitad del siglo XIII. El nacimiento de sus instituciones de gobierno local, en Metropolis Totivs Hispaniae. Catálogo de la Exposición sobre el 750 Aniversario de la incorporación de Sevilla a la Corona de Castilla (Sevilla, 1998), pp. 73-89.

${ }^{33}$ Iglesia Ferreirós, Aquilino, Derecho municipal, derecho señorial, derecho regio, cit. (n. 19), pp. 136 ss.

${ }^{34}$ Encontramos la actuación de estos alcaldes del rey en concejos a los que Alfonso X concede el Fuero Real (sirva el ejemplo burgalés), en aquellos municipios a los que, o bien Alfonso X o bien su padre, les habían concedido el Fuero Juzgo en su versión toledana (paradigmático el caso hispalense) e incluso en municipios carentes a mediados del siglo XIII de un fuero de origen regio (como Salamanca).

${ }^{35}$ GonzÁlez Jiménez, Manuel, La creación del derecho local y territorial, cit. (n. 29), p. 134. 
por Alfonso X: unificación jurídica y renovación del contenido del derecho. Aunque por razones de claridad expositiva trataremos ambas realidades de forma individualizada, quisiéramos subrayar el grado de complementariedad existente entre ellas. De hecho, el monarca intentará llevar a la práctica estas variables de forma conjunta, aprovechando sus esfuerzos encaminados a conseguir una mayor homogeneización en los sistemas normativos para introducir principios ajenos a la tradición jurídica de sus reinos.

Deberíamos tener en cuenta, sin embargo, que este doble propósito del proyecto legislativo alfonsí no constituye una realidad radicalmente diferenciada a la de otras zonas de Occidente. Aunque con particularidades regionales, el avance en la unificación de los sistemas normativos sobre la base del ius commune obedece a una tendencia general, a todo un nuevo estadio de la Historia del Derecho europeo ${ }^{36}$. Por tanto, no debe extrañarnos que, dentro del pensamiento jurídico-político de Alfonso X, resultase imprescindible no sólo reivindicar la facultad del monarca para crear derecho, sino también la de intentar que este fuese lo más uniforme posible para los distintos territorios de la Corona de Castilla. De ahí que durante el transcurso de su reinado el monarca programase acabar con la heterogeneidad de iura propia o, lo que es lo mismo, combatir la multiplicidad de ordenamientos mediante un único código con carácter general para el conjunto de sus dominios. Dada la entidad del proyecto, cabría preguntarse por los instrumentos de los que se va a valer para tales objetivos; en otras palabras, ¿qué tipo de materiales van a ser los elegidos para avanzar en la unificación jurídica?

En este sentido lo primero que debemos tener presente es que nos encontramos ante uno de los aspectos del proyecto legislativo alfonsí donde resulta más oportuno descartar una interpretación excesivamente rígida. Por este motivo no estaría de más recordar la operatividad de dos variables: la influencia de las diferentes circunstancias políticas en las decisiones llevabas a cabo por Alfonso X en materia jurídica y, directamente relacionado con ello, la evolución de su actuación legislativa a lo largo de más de treinta años al frente del trono castellano. Y decimos esto porque, precisamente en lo que atañe a la unificación jurídica de sus reinos, podemos comprobar que la actividad legislativa del rey irá transformándose con el paso del tiempo. Así, en función de los objetivos perseguidos en cada momento como, sobre todo, de la naturaleza de los materiales jurídicos empleados, podemos establecer dos etapas en esta progresiva integración de los sistemas normativos.

En una primera fase el monarca comenzará a combatir el particularismo jurídico mediante una política de concesión de la misma normativa municipal a varios concejos. Pese a la utilización para ello de dos instrumentos legales disímiles -representado uno por algunos fueros anteriores, y otro por la elaboración y

${ }^{36}$ Lalinde Abadía, Jesús, Iniciación histórica al derecho español (Barcelona, 1989), p. 13. Véase también KORSCHAKER, Paul, Europa y el derecho romano, cit. (n. 1), pp. 58-63; TOMÁS Y VAliente, Francisco, Manual de historia del derecho español (Madrid, 1981), pp. 200-203; Wolf, Armin, El movimiento de legislación y de codificación en Europa en tiempos de Alfonso X el Sabio, en Miguel Rodríguez, Juan Carlos de; Muñoz Fernández, Ángela; Segura Graíño, Cristina (eds.), Alfonso X el Sabio, vida obra y época (Madrid, 1989), pp. 31-37. 
difusión de su propio fuero- nos encontramos ante un material jurídico bastante respetuoso con la tradición castellano-leonesa.

Será sin embargo en una segunda etapa de su programa normativo, mucho más ambiciosa, cuando Alfonso X no sólo conciba proyectar la validez de un único corpus con fuerza legal para el conjunto de los territorios incluidos en la Corona de Castilla, sino que decida romper abiertamente con la tradición jurídica de sus reinos para dar entrada al derecho común. De esta última etapa de la actuación legislativa alfonsí, en tanto y en cuanto implica una renovación del contenido del derecho, nos ocuparemos en el tercer apartado del presente trabajo.

Centrándonos pues en la primera de las dos fases referidas, hay un par de elementos que permiten caracterizarla: homogeneización parcial de los sistemas normativos y utilización de principios jurídicos respetuosos con la tradición castellano-leonesa. Aun así, dentro de estos iniciales intentos por limitar la multiplicidad de derechos propios podemos diferenciar, a su vez, la puesta en marcha de una doble política. Por una parte, el monarca no tendrá excesivos reparos en hacer un profuso uso de una serie de fueros anteriores a su reinado, siempre y cuando se correspondan con un derecho de origen regio ${ }^{37}$. Por otro lado, para determinados territorios Alfonso X elaborará un nuevo texto legal, diseñando así su propia normativa municipal: el Fuero Real. A través de una serie de masivas concesiones locales, tanto de fueros precedentes como de este nuevo fuero regio, el monarca intentará progresar en la unificación de los sistemas normativos vigentes en sus reinos.

Antes de analizar las más importantes actuaciones legislativas tomadas en ambas direcciones, no estaría de más plantearnos un interrogante: ¿̇tan grave era la situación jurídica existente en la Corona castellana a mediados del siglo XIII como para promover una política de unificación de sus sistemas normativos? En este sentido, las más sugestivas indicaciones sobre el panorama existente en Castilla se encuentran en el Espéculo, donde se advierte que: "entendiendo e veyendo los males que nasçen e sse leuantan en las tierras e en los nuestros rregnos por los muchos ffueros que eran en las villas e en las tierras departidas de muchas maneras, que los vnos iudgauan por ffueros de libros minguados e non conplidos e los otros sse iudgan por ffazannas dessaguissadas e ssin derecho, e los [que] aquelos libros minguados tenien por que sse iudgauan algunos rráyenlos e camíauanlos commo ellos sse querían a pro de si e a danno de los pueblos. Onde por todas estas rrazones sse minguaua la iustiçia e el derecho, porque los que auien de iudgar non podian çiertamiente nin conplidamiente dar los juyzios, e los que rreçebien el danno non podien auer derecho assí commo deuien" 38 .

¿Realmente la situación jurídica era así de desastrosa o, por el contrario, se trata más bien de una argucia retórica del rey para intentar justificar su proyecto? En el momento de acceder al trono Alfonso X, la situación foral castellano-leonesa podría aglutinarse en torno a cuatro grandes familias principales. La primera de ellas es la del Fuero de Benavente, que ya antes de 1252 se había difundido por el

${ }^{37}$ Iglesia Ferreirós, Aquilino, Derecho municipal, derecho señorial, derecho regio, cit. (n. 19), p. 136.

${ }^{38}$ Espéculo, Proemio. 
noroeste del reino leonés. La segunda se correspondería con el Fuero de LogroñoVitoria. La tercera gira en torno a la gran familia del viejo Liber visigodo o Fuero Juzgo, con plena validez en León, Toledo, y utilizado también para dotar de una misma base legal a los nuevos concejos andaluces y murcianos. Finalmente, la cuarta familia foral se identifica con fueros de Frontera o de la Extremadura.

Sin embargo, relativamente al margen de este cuadro quedaba el área de Castilla la Vieja, esto es, las actuales provincias de Burgos, Valladolid y Palencia, donde existía una mínima vigencia del derecho regio, puesto que estos territorios continuaban rigiéndose por sistemas normativos de tipo consuetudinario basados en sentencias o fazañas de sus propios jueces, así como en la costumbre no escrita. En definitiva, en el momento de iniciar su reinado, Alfonso X era consciente de que sus reinos no sólo acusaban una importante dispersión normativa, sino que en determinadas regiones existía un tipo de derecho que, dentro de su ideario jurídico-político, no tenía razón de $\operatorname{ser}^{39}$.

Como adelantábamos un poco más arriba, los instrumentos jurídicos con los que el rey comenzará a corregir esta multiplicidad se corresponden, en un primer momento, con una serie de fueros municipales anteriores a su reinado. En este caso el monarca se decidió por la utilización de tres de esas familias forales señaladas: Benavente, Logroño-Vitoria y Fuero Juzgo. Aunque nos encontramos ante unas plataformas normativas anteriores, estos fueros seguían constituyendo un derecho de origen regio, de ahí que Alfonso X no hiciese nada por alterar la situación jurídica en este sentido heredada. Es más, el monarca se valió de tales leyes como instrumentos de su inicial política foral, utilizándolas para combatir la heterogeneidad jurídica castellano-leonesa.

En lo que respecta al Fuero de Benavente, aunque se trata de una normativa que ya en tiempos de Alfonso IX de León había conocido cierta difusión por Galicia, será sin embargo el rey Sabio quien más contribuya a incrementar su expansión territorial, haciendo una amplísima utilización del mismo para unificar jurídicamente dos importantes espacios: uno en Galicia y otro, más relevante si cabe, en Asturias ${ }^{40}$. Mediante una política de masivas concesiones del Fuero de Benavente, Alfonso X llegó a crear una nueva familia foral en el noroeste peninsular, conformando un amplio espacio geográfico regido por una misma normativa que venía a cumplir así una destacada función unificadora ${ }^{41}$.

Si nos desplazamos hasta el cuadrante más nororiental de la Corona de Castilla podremos encontrar una política bastante parecida, pero que en este caso va a tener como principal protagonista al Fuero de Logroño. Fue este uno de los fueros de

\footnotetext{
${ }^{39}$ Para la concepción del monarca este derecho ni siquiera era digno de tal nombre, pues algunas zonas "non ouieron fuero fasta en el nuestro tiempo, e iudgáuasse por fazannas e por aluedrios departidos de los omnes e por usos desaguisados e sin derecho", cfr. Fuero Real, Proemio.

${ }^{40}$ Ruiz de la PeÑa Soler, José Ignacio, La expansión del Fuero de Benavente, en Archivos Leoneses, 24 (1970), pp. 299-307; ÉL MISMo, Poblamiento y cartas pueblas de Alfonso Xy Sancho IV en Galicia, en Homenaje a don José Ma Lacarra en su jubilación del profesorado. Estudios Medievales (Zaragoza, 1977, III), pp. 27-60.

${ }^{41}$ Ruiz de la PeÑa Soler, José Ignacio, Las "polas" asturianas en la Edad Media. Estudio y Diplomatario (Oviedo, 1981), p. 87.
} 
mayor éxito en cuanto a difusión territorial se refiere, ya que desde tiempos de Alfonso VI había sido una normativa ampliamente otorgada tanto por monarcas castellanos como navarros ${ }^{42}$. Alfonso X continuó con esta misma estrategia, $\mathrm{y}$ en reiteradas ocasiones otorgó el Fuero de Logroño -en muchos casos ya como Fuero de Vitoria- a un amplio número de villas y ciudades del norte peninsular, consiguiendo unificar gran parte del espacio foral alavés y guipuzcoano ${ }^{43}$.

Nos encontramos pues ante dos familias forales, Benavente y Logroño-Vitoria, que, fruto de su origen regio, fueron profusamente utilizadas por el monarca en un intento de unificar jurídicamente sus respectivas áreas de difusión, homogeneizando mediante profusas concesiones de un mismo fuero el derecho local vigente en un amplísimo espacio del norte de la Corona, el cual se extendía desde Puebla de Muros -allá en el Finisterre gallego- hasta la misma frontera castellana con el reino de Navarra. Pero, al acceder al trono Alfonso X, el Fuero Juzgo gozaba de un nivel de difusión todavía más relevante que el de las dos familias forales descritas. No en vano el viejo Liber era el derecho que continuaba vigente tanto en tierras leonesas como en Toledo y, además, en tiempos de Fernando III había sido el arquetipo de normativa municipal elegido para dotar de la misma base legal a los nuevos territorios conquistados, es decir, a buena parte de la Andalucía del Valle del Guadalquivir y al reino de Murcia ${ }^{44}$. ¿Qué sucede entonces con este derecho en tiempos de Alfonso X?

En relación con el Fuero Juzgo, de nuevo vemos cómo el rey no tendrá excesivos reparos en continuar con un tipo de política previamente desarrollada por sus ascendientes. Consecuentemente, el importante grado de difusión de este derecho permanecerá vigente durante su reinado, aunque a partir de ahora vaya a ser concedido ya como Fuero de Córdoba, o bien como Fuero de Sevilla ${ }^{45}$. En este sentido merece ser subrayado el protagonismo que desde fechas tempranas va a alcanzar el Fuero de Sevilla, fruto de su pronta conversión en auténtica normativa modelo que el monarca exportará a la mayor parte de las ciudades y villas andaluzas. No conviene olvidar la posible conexión entre este importante grado de difusión del fuero sevillano y sus propias características. Nos estamos refiriendo, sobre todo, a la brevedad del Fuero de Sevilla; una realidad que lo convertía en un tipo de normativa municipal que dejaba las puertas abiertas a la Corona para la creación de derecho en aquellos aspectos que, por una más que probable premeditada omisión, así se considerase oportuno. Es más, mediante

${ }^{42}$ Barrero García, Ana María, El Fuero de Logroño, en Sesma Muñoz, José Ángel (dir.), Historia de la ciudad de Logroño. II: Edad Media (Logroño, 1995), pp. 169-233.

${ }^{43}$ Martínez Díez, Gonzalo, Poblamiento y ordenamiento juridico en el País Vasco. El estatuto jurídico de la población rural y urbana, en Las formas del poblamiento en el señorio de Vizcaya durante la Edad Media (Bilbao, 1978), pp. 129-169.

${ }^{44}$ GonZÁlez Jiménez, Manuel, Fernando III el Santo, legislador, en Minervae Baeticae. Boletín de la Real Academia Sevillana de Buenas Letras, 29 (2001), pp. 111-131.

${ }^{45}$ González Jiménez, Manuel, La creación del derecho local y territorial, cit. (n. 29), pp. 143-146. Para la política foral de Alfonso X en el reino de Murcia véase CERDÁ RuIz-FunEs, Joaquín, Estudios sobre instituciones jurídicas medievales de Murcia y su reino (Murcia, 1987), pp. 11-47, así como la colección diplomática de TORREs FonTEs, Juan, Documentos de Alfonso X el Sabio. Colección de Documentos para la Historia del Reino de Murcia (Murcia, 1963). 
esta misma política de unificación jurídica basada en la inicial normativa sevillana se intentará implantar un modelo de organización municipal intervenido por la monarquía a través de la designación de oficios concejiles, especialmente de cargos relacionados con la administración de justicia.

Ahora bien, de todos aquellos territorios que formaban parte de la Corona, no cabe duda de que era la zona de Castilla la Vieja donde la situación jurídica se mostraba especialmente grave para un monarca imbuido de que sólo al rey le correspondía legislar. Aunque la calificación de este ámbito geográfico como "país sin leyes" quizás resulte excesiva ${ }^{46}$, lo que sí resulta evidente es el escaso nivel de aplicación que a mediados del siglo XIII el derecho de origen regio presentaba en las actuales provincias de Burgos, Valladolid y Palencia ${ }^{47}$. De hecho, salvando puntuales excepciones, era este un espacio que continuaba rigiéndose por un derecho particularista y tradicional, basado en su mayor parte en sentencias o fazañas de sus propios jueces y, por tanto, ajenos a cualquier tribunal controlado por el rey. Por ello resulta lógico que, desde una concepción jurídico-política como la de Alfonso X, pronto se pensase en poner remedio a tal situación.

Precisamente para intentar corregir esta realidad, así como para comenzar a poner coto a la libre creación de derecho, desde los primeros años de su acceso al trono Alfonso X comenzará a difundir un nuevo texto legal: su propio fuero. Pese a la existencia de un importante debate en torno a la autoría y fecha de redacción del Fuero Real ${ }^{48}$, la mayor parte de los especialistas está de acuerdo en que nos encontramos ante una obra elaborada al principio del reinado ${ }^{49}$. De la misma forma, tampoco ha de sorprendernos que fuese aquel territorio donde ese particularismo jurídico revestía mayor vigor, esto es, el área de Castilla la Vieja,

${ }^{46}$ Guilarte Zapatero, Alfonso, Castilla, pais sin leyes (Valladolid, 1989). Algunos historiadores hablan de Castilla como tierra o país sin leyes en el sentido de decaimiento del Fuero Juzgo, cfr. SÁnChez CASAdo, Galo, Para la historia de la redacción del antiguo derecho territorial, en $A H D E$., 6 (1929), pp. 260-328.

${ }^{47}$ Iglesia Ferreirós, Aquilino, Derecho municipal, derecho señorial, derecho regio, cit. (n. 19), p. 136.

${ }^{48}$ Véase n. 9.

${ }^{49}$ Dejaremos al margen la polémica en torno a si la iniciativa de la redacción del Fuero Real correspondió a Alfonso X o a Fernando III. De la misma forma tampoco vamos a reflexionar aquí sobre su posible autoría, simplemente nos contentaremos con traer a colación la disparidad entre dos de los autores que más decididamente se han posicionado sobre el tema. Por un lado encontramos las opiniones del profesor Pérez Martín, quien apuesta por vincular la elaboración del Fuero Real a uno de los más destacados juristas del entorno de Alfonso X: Jacobo de Giunta, cfr. PÉrez MARTín, Antonio, El estudio de la recepción del derecho común en España, en I Seminario de Historia del Derecho y derecho privado (Barcelona, 1985), p. 292; ÉL MISMO, Jacobo de las Leyes: datos biográficos, en Glossae: Revista de Historia del Derecho Europeo, 5-6 (1994), pp. 279-332. Por otra parte tenemos la postura más cauta de Martínez Díez quien, tras rechazar la interpretación -en otro momento por él defendida- de vincular la autoría del Fuero Real con Fernando Martínez de Zamora, cfr. Martínez DíEz, Gonzalo, Los comienzos de la recepción del derecho romano en España y el Fuero Real, cit. (n. 2), pp. 261-262, apuesta por la imposibilidad de individualizar a ningún jurista o grupo de juristas como autores materiales de la obra, $c f r$. Martínez Díez, Gonzalo (ed.), Leyes de Alfonso X, II: Fuero Real (Ávila, 1988), p. 106. 
el elegido por el monarca para comenzar una activa política de concesiones de su propio fuero ${ }^{50}$.

En efecto, la expansión del Fuero Real se inicia en 1255, momento en el que Alfonso X decide empezar a otorgarlo como normativa municipal tipo a los concejos de las actuales provincias de Burgos, Palencia y Valladolid que hasta la fecha carecían de un fuero propio, o bien en sustitución del anterior ${ }^{51}$. En cualquiera de ambos casos, en casi todas estas iniciales ocasiones el Fuero Real comienza a concederse a aquellos municipios que no tenían derecho de origen regio: Aguilar de Campoo, Sahagún, Carrión, Burgos, Santo Domingo de la Calzada... Nos encontramos pues ante la elaboración y difusión de un nuevo texto legal destinado a cumplir, en aquellos territorios que según el ideario jurídico-político del monarca carecían de fuero cumplido, la función que por estas mismas fechas estaba desempeñando el Fuero de Benavente en el noroeste de la Corona o el Fuero Juzgo para zonas del sur y levante.

No obstante, muy pronto el monarca decide dilatar la geografía de concesiones del Fuero Real, ampliando sustancialmente su escenario más allá de los límites territoriales de Castilla la Vieja. De hecho, el mayor número de concesiones se produce a partir de 1256, y es entonces cuando Alfonso X comienza a difundir el Fuero Real por la Extremadura castellana -Soria, Peñafiel, Cuéllar, Segovia, Arévalo, Sepúlveda, Ávila-, la Transierra, e incluso llegará a penetrar hasta el reino de Toledo, Murcia y Andalucía ${ }^{52}$. Un territorio este último donde acabamos de comprobar cómo el fuero toledano, ya en su versión como Fuero de Sevilla, estaba siendo utilizado con un sentido muy similar. Desde 1257 las concesiones del nuevo fuero regio se hacen cada vez más esporádicas, continuando vigentes con un ritmo muy dispar hasta 1272 , fecha de la última que tenemos constatada documentalmente ${ }^{53}$.

Aunque inicialmente pudo ser concebido como una normativa municipal diseñada para aquellas villas y ciudades de Castilla la Vieja que carecían de derecho regio, resulta evidente que el Fuero Real conoció una difusión más amplia. Así, podemos defender que este texto sobrepasó ampliamente el estrecho marco

${ }^{50}$ Iglesia Ferreirós, Aquilino, Fuero Real y Espéculo, cit. (n. 9), pp. 170-171.

${ }^{51}$ Véase el mapa de tales concesiones en GONZÁLEZ JimÉnEZ, Manuel, La creación del derecho local y territorial, cit. (n. 29), p. 218. Algunos datos interesantes al respecto en MARTínEz DíEz, Gonzalo, Los comienzos de la recepción del derecho romano en España y el Fuero Real, cit. (n. 2), p. 259; González Mínguez, César, La concesión del Fuero Real a Vitoria, en Historia. Instituciones. Documentos, 28 (2001), pp. 217-229. Obsérvese tanto el importante número de concesiones como su mayor concentración en territorios de Castilla la Vieja y la Extremadura castellana. Sin embargo, O'Callaghan niega estas concesiones individuales del Fuero Real para defender que se le dio a todas las villas de Castilla y Extremadura mediante su promulgación en una asamblea de prelados, nobles y otros hombres de la corte y del reino en Palencia en mayo de 1225, cfr. O’Callaghan, Joseph F., Sobre la promulgación del Espéculo y del Fuero Real, en Estudios en Homenaje a don Claudio Sánchez Albornoz en sus 90 cumpleaños. Anexos de Cuadernos de Historia de España (Buenos Aires, 1985), pp. 178-179.

${ }^{52}$ González Jiménez, Manuel, La creación del derecho local y territorial, cit. (n. 29), pp. 128-130.

${ }^{53}$ Iglesia Ferreirós, Aquilino, Fuero Real y Espéculo, cit. (n. 9), p. 131. 
ciudadano para adquirir un auténtico carácter supra-local. En otras palabras, tal y como hemos tenido la oportunidad de comprobar para los casos del Fuero de Benavente, Logroño-Vitoria o Fuero Juzgo, también el Fuero Real fue utilizado para avanzar en la territorialización del derecho e intentar unificar, bajo una misma normativa municipal de origen regio, un importante espacio político dentro de la Corona.

Sin embargo, a pesar del importante número de villas y ciudades que recibieron el Fuero Real, en todos los casos nos encontramos ante unas concesiones forales de carácter individual. Por ello mismo debemos reconocer que, a lo largo de toda esta primera fase, la política regia de unificación jurídica nunca dejó de ser parcial, fruto de que los únicos avances en esa homogeneidad quedaron circunscritos a aquellos concejos que reciben una nueva normativa municipal de origen regio, ya fuese un fuero anterior al ascenso al trono de Alfonso X, o bien el nuevo fuero diseñado por el monarca. Además, debemos tener presente que, con esta política regia de nuevas concesiones, tanto de fueros anteriores como del Fuero Real, se trata más de completar el derecho que de alterar radicalmente su contenido ${ }^{54}$.

Pero, es más, la concesión del Fuero Real tropezó pronto con una doble resistencia. Por un lado, la oposición más evidente estuvo protagonizada por las propias villas y ciudades a las cuales les había sido otorgado, quienes vieron en el nuevo código una amenaza contra sus fueros de albedrío y, en consecuencia, su tradicional autonomía político-jurídica ${ }^{55}$. Tal es así que, ni siquiera la serie de privilegios concedidos de forma paralela al Fuero Real por Alfonso X a las oligarquías locales, fueron suficientes para captar su colaboración a la hora de renunciar a sus iura propia ${ }^{56}$. Aparte de ello, en el seno de estos municipios tampoco debió sentar muy bien la sustitución de alcaldes foreros por nuevos alcaldes del rey.

Por otra parte, la nueva normativa municipal diseñada por el monarca hubo de enfrentarse también a la desconfianza de importantes sectores de la nobleza. Con la amplia difusión del Fuero Real y, sobre todo, con un progresivo avance del derecho regio, muchos nobles llegaron a temer la pérdida de unos tradicionales privilegios, en buena medida protegidos por anteriores ordenamientos jurídicos que blindaban sus prerrogativas. Aparte de ello, detrás de este rechazo nobiliario subyace una lucha política mucho más amplia en el tiempo y en el espacio, un enfrentamiento multisecular nobleza-monarquía que recorre toda la Baja Edad Media castellana y que, ahora, aparece directamente relacionado con los deseos de Alfonso X de fortalecer del poder regio ${ }^{57}$.

Esta oposición de buena parte del reino a la masiva difusión del Fuero Real

${ }^{54}$ Vallejo Fernández de la Reguera, Jesús, Relectura del Fuero Real, cit. (n. 25), p. 501.

${ }^{55}$ Bermejo Cabrero, José Luis, La idea medieval de contrafuero en León y Castilla, en Revista de Estudios Políticos, 187 (1973), pp. 299-306.

${ }^{56}$ Estos privilegios han sido analizados en GonZÁlez JiméneZ, Manuel, Alfonso X y las oligarquias urbanas de caballeros, cit. (n. 30), pp. 195-214.

${ }^{57}$ Alfonso AnTón, María Isabel, Desheredamiento y desafuero, o la pretendida justificación de una revuelta nobiliaria, en Cahiers de linguistique et de civilisation hispaniques médiévales, 25 (2002), pp. 99-129; EsCalona Monge, Julio, Los nobles contra su rey. Argumentos y motivaciones de la insubordinación nobiliaria de 1272-1273, en Cabiers de linguistique et de civilisation hispaniques médiévales, 25 (2002), pp. 131-162. 
terminó cristalizando en las Cortes de Burgos de 1272. A pesar de que no se ha conservado el Cuaderno de la que tuvo que ser una de las asambleas más movidas del reinado, la documentación emanada de la cancillería regia permite vislumbrar que el monarca no tuvo más remedio que acceder a la petición de los concejos de que les fuesen confirmados sus antiguos privilegios y franquezas, pudiendo así volver a regirse por aquellos fueros y costumbres anteriores a la concesión de la normativa municipal diseñada por Alfonso $\mathrm{X}^{58}$.

\section{RENOVACIÓN DEL CONTENIDO DEL DERECHO}

Como señalábamos con anterioridad, dentro del proyecto legislativo ideado por el rey Sabio concurre una simultaneidad entre los intentos de unificación jurídica y la renovación del contenido del derecho. De la misma forma, y en lo que a esa homogeneización de los sistemas normativos se refiere, también habíamos planteado la existencia de dos grandes etapas a lo largo de sus más de treinta años de reinado. Una vez considerada la primera de ellas en el epígrafe precedente, nos detendremos en el análisis de la segunda, en la cual Alfonso X intentará materializar un programa normativo más ambicioso. Y es que en esta ocasión el monarca no sólo se contentará con minimizar la multiplicidad del derecho mediante la creación de distintos espacios forales, sino que aspirará a conseguir la vigencia de un único código con fuerza legal para todos los territorios incluidos en la Corona. Precisamente será entonces, en medio de tan avanzado estadio de su programa legislativo, cuando el rey decida romper con la herencia precedente para apostar por la renovación del contenido del derecho.

Acabamos de referirnos a una ruptura con respecto a la tradición heredada, a una innovación en los principios jurídicos vigentes en la Castilla de la segunda mitad del siglo XIII, pero, ¿con qué derecho hacerlo? ¿de dónde tomar los nuevos materiales para llevar a cabo esta renovación? Resulta lógico que, en una fase tan madura de su proyecto, los propósitos de Alfonso X pasasen por introducir en Castilla el derecho más técnico y desarrollado de la Europa del momento. Además, los principios insertos en este derecho común venían a favorecer sus particulares reivindicaciones jurídico-políticas ${ }^{59}$.

Sin embargo, y al igual que sucede con el resto del programa legislativo alfonsí, esta renovación del contenido del derecho también tendrá un carácter gradual. Así, en la que podemos considerar como la primera obra jurídica en la que se materializa esa recepción, los progresos dados son todavía limitados. Nos referimos al Espéculo, un texto donde, más que avanzar en la admisión del ius commune, lo que se ensaya es la formulación de un código legislativo con carácter general para la totalidad de los territorios incluidos en la Corona.

De esta forma, dentro del ideario jurídico-político de Alfonso X el Espéculo

\footnotetext{
${ }^{58}$ Iglesia Ferreirós, Aquilino, Las Cortes de Zamora de 1274 y los casos de corte, en AHDE., 41 (1971), pp. 953-957.

${ }^{59}$ MacDonald, Robert A., Derecho y politica: el programa de reforma politica de Alfonso $X$, en Burns, Robert Ignatius (comp.), Los mundos de Alfonso el Sabio y Jaime el Conquistador. Razón y fuerza en la Edad Media (Valencia, 1990), p. 229.
} 
vino a cubrir la necesidad sentida de un único libro de leyes que acabara definitivamente $-y$ no de modo parcial como lo había conseguido mediante la masiva concesión de distintas normativas municipales de origen regio- tanto con la multiplicidad de fueros como con la vigencia de juicios realizados por fazannas desaguisadas e sin derecho. En otras palabras, nos encontramos ante una obra proyectada como auténtico nervio orgánico de la constitución política del reino: "veyendo e entendiendo todos estos males e todos estos dannos que sse leuantauan por todas estas rrazones que dicho auemos, ffeziemos estas leys que sson escriptas en este libro, que es espeio del derecho porque se iudguen todos los de nuestros rregnos e de nuestro ssennorio, el cual es lunbre a todos de ssaber e de entender las cosas que sson pertenesçientes en todos los ffechos para conosçer el pro e el danno e enmendarsse de las menguas que dichas auemos, e más a los iudgadores por ó ssepan dar los iuyzios derechamiente e guardar a cada vna de las partes que ante ellos venieren en ssu derecho e sigan la ordenada manera en los pleitos que deuen"60.

Además, desde el punto de vista de la renovación del contenido del derecho, el Espéculo es el primer texto donde se ponen de manifiesto los deseos del monarca de dar entrada, dentro del panorama jurídico de la Castilla de mediados del siglo XIII, al derecho común. Ahora bien, debemos tener en cuenta que la presencia de los nuevos principios jurídicos de inspiración romano-canónica es aún restringida. De hecho, esta escasa incidencia podemos constatarla en el propio prólogo de la obra, donde se reconoce que: "catamos e escogiemos de todos los ffueros lo que más ualie e lo meior pusiémoslo, e tanbién del ffuero de Castiella commo de León, commmo de los otros logares que fallamos que eran derechos e con rrazón" ${ }^{1}$. De acuerdo con este preámbulo podríamos pensar que para la elaboración del Espéculo sólo se seleccionaron materiales jurídicos acordes con la tradición. Sin embargo, este libro es más que una simple recopilación de lo mejor de los fueros de León y de Castilla, ya que mediante su redacción se inicia una renovación del contenido del derecho, debido fundamentalmente a dos razones principales.

Por un lado, y a pesar de ser el Espéculo un texto inconcluso, parece indudable que nos encontramos ante una obra tremendamente madura, muy técnica y elaborada, lo que pone de manifiesto que obedece al quehacer de expertos juristas; realidad esta que nos permite colocarla en la órbita del nuevo derecho común ${ }^{62}$. Por otra parte, además de la selección de lo mejor de los fueros de León y de Castilla, el Espéculo incorpora también algunos de los principios jurídicos que comenzaban a circular por la Europa de aquel entonces, advirtiéndose una notoria influencia del derecho romano-canónico ${ }^{63}$.

Y es que desde su propia concepción este texto aparece proyectado como una codificación ambiciosa, extensa y detallista, y esto es así tanto en el alcance como

${ }^{60}$ Espéculo, Proemio. Véase también Pérez-Prendes y MuÑoz de Arracó, José Manuel, La obra jurídica de Alfonso X, en Alfonso X. Catálogo de la Exposición de Toledo, 1984 (Madrid, 1984), pp. 52-53.

${ }^{61}$ Espéculo, Proemio.

${ }^{62}$ García Díaz, Jesús, La Europa de Alfonso X el Sabio, cit (n. 14), pp. 263-290.

${ }^{63}$ Pérez-Prendes y Muñoz de Arracó, José Manuel, Las leyes de Alfonso el Sabio, cit. (n. 4), pp. 78 ss. 
en el amplísimo tratamiento de las distintas cuestiones jurídicas. De hecho, en el Espéculo las leyes no se limitan a contener una parte preceptiva, como sucede en el Fuero Real, sino que van acompañadas de una serie de consideraciones didácticas y filosóficas que, en la mayoría de las ocasiones, explican el sentido de términos e instituciones jurídicas latinas. Tal entidad adquiere esta preocupación por argumentar la legalidad y conveniencia de los preceptos recogidos, que en muchos casos se termina justificando su significado con consideraciones de tipo moral $^{64}$. Se convierte así el Espéculo en el primer texto jurídico caracterizado por presentar un doble carácter: legal y doctrinal, inaugurándose un estilo suasorio que estará igualmente presente en las Partidas ${ }^{65}$.

Como habrá podido comprobarse, en un pasaje anterior hacíamos alusión al carácter inacabado del Espéculo. Efectivamente, buena parte de la historiografía que se ha ocupado de su estudio defiende que nos encontramos, con toda probabilidad, ante un texto intencionadamente abandonado antes de haber sido concluido $^{66}$. Por ello mismo -y salvo alguna excepción ${ }^{67}$ - la mayoría de los especialistas sostiene que esta obra nunca llegó a ser promulgada. Si seguimos con la misma lógica tendremos que reconocer que el Espéculo nunca tuvo vigencia legal en la Corona de Castilla, pese a que en su prólogo se proyectase que: "damos ende libro en cada villa sseellado con nuestro sseello de plomo e touiemos este escripto en nuestra corte, de que sson ssacados todos los otros que diemos por las villas, porque ssi acaesçiere dubda ssobre los entendimientos de las leys e sse alçassen a nos que sse libre la dubda en nuestra corte por este libro que ffeziemos"68.

A pesar de ello, pensamos que el propio hecho de programar el envío simultáneo del Espéculo a todas las villas y ciudades induce a pensar que nos encontramos ante un texto originariamente destinado a intentar hacer efectiva, por vez primera, una ley con alcance territorial, un código que viniese a superar definitivamente aquel particularismo normativo. ¿Por qué interrumpir entonces la redacción de una obra tan madura desde su propia concepción y emprender la elaboración de un nuevo corpus jurídico? Dicho de otro modo, ¿cuáles fueron los motivos que explican que el Espéculo resultase un frustrado e inconcluso proyecto legislativo?

Quizás sea en este punto, es decir, en el supuesto abandono del Espéculo para emprender la redacción de las Partidas, donde de forma más meridiana se manifiesta la influencia de las distintas circunstancias del reinado de Alfonso X en la evolución de su ideario jurídico-político y, en consecuencia, de su propio proyecto legislativo. Nos estamos refiriendo al fecho del Imperio y su más que probable relación con los inicios de la elaboración de la más ambiciosa de las

${ }^{64}$ Pérez Martín, Antonio, Hacia un derecho común europeo cit. (n. 10), p. 121.

${ }^{65}$ Torres Fontes, Juan, Murcia y Las Partidas, en AHDE., 34 (1954), p. 534.

${ }^{66}$ Iglesia Ferreirós, Aquilino, Fuero Real y Espéculo, cit. (n. 9), p. 167; Martínez Díez, Gonzalo (ed.), Leyes de Alfonso X, I: Espéculo (Ávila, 1985), p. 8.

${ }^{67} \mathrm{La}$ representada por O’Callaghan, quien defiende que el Espéculo se promulgó, juntamente con el Fuero Real, en una asamblea reunida en Palencia en 1255, cfr. O’Callaghan, Joseph F., Sobre la promulgación del Espéculo y del Fuero Real, cit. (n. 51), p. 177.

${ }^{68}$ Espéculo, Proemio. 
obras jurídicas patrocinadas por el rey Sabio: las Partidas ${ }^{69}$. No pretendemos aquí abordar la polémica -en buena medida inconclusa- entablada en torno a los posibles motivos que llevaron al monarca a embarcarse, en tan poco espacio de tiempo, en la redacción de un nuevo y monumental código ${ }^{70}$. Simplemente nos limitaremos a dejar constancia de las más que posibles conexiones entre el comienzo de la composición de las Partidas, la llegada a Castilla de los embajadores de la ciudad de Pisa y la oferta del título imperial a Alfonso X, y la interrupción de la redacción del Espéculo.

En este sentido no carece de lógica que el monarca pensase que, para hacer frente a una plausible elección imperial ${ }^{71}$, no fuese suficiente una obra como el Espéculo. Si bien es cierto que este texto contaba ya con algunos principios de inspiración romano-canónica, también lo es que se encontraba bastante apegado a la tradición jurídica hispana, concretamente castellano-leonesa. Resulta por tanto factible que fuese a raíz de la llegada de la embajada pisana y la oferta de la corona del Sacro Romano Imperio cuando el rey decidiese iniciar la elaboración de un código digno de un emperador y que, por ello mismo, sirviese para reforzar su posición como aspirante al título. En consecuencia, habría sido este nuevo y trascendental acontecimiento de su reinado el desencadenante de un cambio en la política legislativa del monarca quien, ante la perspectiva de verse coronado emperador, decide consumar definitivamente la renovación jurídica de sus reinos con un nuevo proyecto más europeo y universal sustentado en el ius commune ${ }^{72}$.

En efecto, las Partidas consuman la recepción del derecho común en la Corona castellana ${ }^{73}$. Se trata de una obra monumental en la que tienen cabida los más diversos saberes, y en la que se abandonan sin reparos los mejores fueros de Castilla y de León para dar entrada al nuevo derecho romano-canónico. Por

\footnotetext{
${ }^{69}$ Un repaso a la ingente bibliografía sobre Las Partidas en CradDOCK, Jerry R., The Partidas: Bibliographical Notes, en Burns, Robert Ignatius (ed.), Las Siete Partidas. Volume One. The Medieval Church. The World of Clerics and Laymen (Philadelphia, 2001), pp. 41-48.

${ }^{70}$ Para este tema SáncheZ-Arcilla Bernal, José, La obra legislativa de Alfonso X, cit. (n. 7), pp. 17-81.

${ }^{71}$ Sobre las aspiraciones imperiales de Alfonso X véase ItURMEndi Morales, José, En torno a la idea de Imperio en Alfonso X el Sabio, en Revista de Estudios Políticos, 182 (1972), pp. 88-155; Ayala Martínez, Carlos de, Alfonso X: Beaucaire y el fin de la pretensión imperial, en Hispania, 47 (1987), pp. 5-31; ÉL MISMO, Directrices fundamentales de la política peninsular de Alfonso X (Madrid, 1986), pp. 168-179; EsTEPA DíEZ, Carlos, Alfonso X y el fecho del Imperio, en Revista de Occidente, 43 (1984), pp. 43-54; ÉL MISMO, El fecho del Imperio y la politica internacional en la época de Alfonso X, en MondéJAR CuMPIÁn, José (coord.), Estudios alfonsíes: lexicografía, lírica, estética y política internacional en la época de Alfonso X (Granada, 1985), pp. 189-205; Wolf, Armin, Derecho electivo y sucesión hereditaria en los reinos y en el Imperio de Alfonso el Sabio, en Pérez Martín, Antonio (ed.), España y Europa: un pasado jurídico común, cit. (n. 1), pp. 223257; O’Callaghan, Joseph F., El Rey Sabio. El reinado de Alfonso X de Castilla, cit. (n. 5), pp. 243-260; González Jiménez, Manuel Alfonso X el Sabio, cit. (n. 3), pp. 273-293.

${ }^{72}$ Pérez Martín, Antonio, Hacia un derecho común europeo, cit. (n. 10), p. 122.

${ }^{73}$ MacDonald, Robert A., Derecho y política: el programa de reforma politica de Alfonso X, cit. (n. 59), p. 211; PIÑA Homs, Román, Alfonso X el Sabio: Universalidad frente a localismo, cit. (n. 3), pp. 476 ss.; Giménez y Martínez de Carvajal, José, El Decreto y Las Decretales, fuentes de la Primera Partida de Alfonso el Sabio, en Anthologica Annua, 2 (1954), pp. 239-248.
} 
tanto, nos encontramos ante el texto que mejor materializa esa aspiración alfonsí de renovación de la vida jurídica de sus reinos. Ahora bien, ni la vinculación de las Partidas con las aspiraciones imperiales del monarca, ni esta decidida apuesta por el derecho común, son motivos suficientes para que consideremos a este gigantesco corpus jurídico como una obra aislada, de concepción única por parte de Alfonso X. Frente a ello, y como hemos venido haciendo a lo largo de estas páginas, pensamos que sería preferible acercarse a las Partidas como brillantísimo epílogo de un ambicioso y dinámico programa legislativo.

Además, probablemente sea en el caso de esta última obra salida del scriptorium alfonsí en la que aparezcan, al lado de este significado político que nos viene ocupando, motivaciones de cultura jurídica igualmente presentes en la actuación legislativa desplegada por el monarca ${ }^{74}$. Quisiéramos recalcar con ello que las Partidas también pudieron ser concebidas como una recopilación del mejor saber jurídico de su tiempo ${ }^{75}$. En este sentido, y al igual que estaba haciendo con otros tantos saberes como la astrología o la historia, parece que la actuación de Alfonso $\mathrm{X}$ en lo que a la ciencia jurídica se refiere no supuso ninguna excepción, de ahí que impulsase reunir lo mejor de esta determinada rama del saber ${ }^{76}$. Y para ello el rey no dudó en acudir al derecho más técnico, culto y desarrollado que la Europa del momento podía ofrecerle ${ }^{77}$.

En cualquier caso, debemos tener presente que las Partidas no llegaron a ser promulgadas durante el reinado de Alfonso X. Consecuentemente, y al igual que sucede con el Espéculo, este monumental corpus jurídico tampoco tuvo fuerza legal en la Corona de Castilla ni durante el reinado del rey Sabio ni en el de sus más inmediatos sucesores. Bien porque el verdadero destino de las Partidas fuese otro $^{78}$, bien porque el fracaso del Espéculo indujera al rey a convertirlas en una obra fundamentalmente doctrinal ${ }^{79}$, o bien por la contingencia de ambos factores y que desde un principio el monarca proyectase una labor de cultura jurídica, lo cierto es que este magno código no tuvo fuerza de ley hasta mucho tiempo después. De hecho, tendremos que esperar al reinado de Alfonso XI, y en concreto hasta el Ordenamiento promulgado en las Cortes de Alcalá de Henares de 1348,

${ }^{74}$ Piña Homs, Román, Alfonso X el Sabio: Universalidad frente a localismo, cit (n. 3) pp. 480-486. También puede encontrarse una identificación entre razones de política legislativa y Fuero Real, y razones de cultura jurídica y Partidas en Clavero Salvador, Bartolomé, Temas de historia del derecho: derecho de los reinos (Sevilla, 1977), p. 97.

${ }^{75}$ Procter, Evelyn S., Alfonso X de Castilla, patrono de las letras y del saber, cit. (n. 5), p. 62.

${ }^{76}$ MacDonald, Robert A., Derecho y politica: El programa de reforma politica de Alfonso X, cit. (n. 59), p. 211; Torres Fontes, Juan, Murcia y las Partidas, cit. (n. 65), p. 544.

${ }^{77}$ García Díaz, Jesús, La Europa de Alfonso Xel Sabio, cit. (n. 14), pp. 267-289; Él mismo, El fenómeno del mercado en la obra legislativa de Alfonso X el Sabio, en Historia. Instituciones. Documentos, 38 (2011), pp. 111-140.

${ }^{78}$ GIBERT Y SÁNCHEZ DE LA VEGA, Rafael, 360 preguntas y respuestas sobre historia del derecho español, addenda para el curso primero en la Universidad Nacional a Distancia (Madrid, 1982) pp. 126 ss.; Iglesia Ferreirós, Aquilino, La labor legislativa de Alfonso X, cit. (n. 9) pp. 455-456.

${ }^{79}$ GarCía-Gallo de Diego, Alfonso, Nuevas observaciones sobre la obra legislativa, cit. (n. 9), pp. 609-670. 
para comprobar que las Partidas alcanzan verdadera vigencia legal ${ }^{80}$. No será pues hasta mediados del siglo XIV cuando la más monumental y ambiciosa de las obras salidas del scriptorium alfonsí reciba sanción jurídica, con carácter supletorio en tercer grado, en la Corona de Castilla ${ }^{81}$.

\section{Conclusiones}

A lo largo de estas páginas se ha podido comprobar la destacada influencia del ideario jurídico-político de Alfonso X en la génesis y ulterior desarrollo de su proyecto normativo. De ahí que la intensa actividad legislativa auspiciada por este monarca obedezca a una realidad más compleja y poliédrica que el inicio de la recepción del derecho común en la Corona de Castilla.

Parece pues conveniente abandonar una imagen estática y monolítica de la actuación de Alfonso X en el ámbito del derecho, pues no concibió de una sola vez su programa legislativo, ni este permaneció inalterable a lo largo del tiempo. Desde la utilización de leyes municipales anteriores hasta la composición de las Partidas, pasando por la elaboración de su propio fuero o el ensayo del Espéculo como código con fuerza legal en toda la Corona, el proyecto normativo alfonsí irá evolucionando y adaptándose a diferentes momentos y circunstancias del reinado. Precisamente por ello, en todas las decisiones llevadas a cabo por el monarca en materia jurídica se evidencian también razones de política legislativa que, en buena medida, obedecen a su particular concepción del poder real y del propio derecho. Este singular ideario jurídico-político queda articulado en torno a tres principios fundamentales que, a la postre, se convierten en los ejes vertebradores de su programa normativo.

En primer lugar, la reivindicación del monopolio regio en la creación de derecho y, por consiguiente, el creciente control monárquico de la administración de justicia. En segunda instancia la unificación jurídica de sus reinos, esto es, validar un código legal con el que poner coto a la heterogeneidad de iura propia. Y finalmente la renovación del contenido del derecho vigente en sus reinos, dando así entrada al nuevo derecho común.

Ahora bien, en el presente trabajo también se ha podido verificar que una cosa fue el teórico proyecto legislativo progresivamente concebido por Alfonso X y otra, muy diferente, el grado de aplicación que realmente tuvo. Precisamente por tratarse de un programa tan ambicioso e innovador, su plasmación efectiva resultó mucho más limitada de lo que los planes regios hubiesen deseado.

\footnotetext{
${ }^{80}$ Así lo reconoce, en el citado Ordenamiento, el propio Alfonso XI: "et los pleitos e contiendas que se non podieren librar por las leyes deste libro [Fuero Real] e por los dichos fueros, mandamos que se libren por las leyes contenidas en los libros de las siete Partidas que el Rey don Alfonso nuestro visauuelo mando ordenar, commo quier que fasta aqui no se falla que fuesen publicadas por manado del Rey ni fueron auidas nin rresçibidas por leyes", cfr. Ordenamiento de leyes que el rey D. Alfonso XI hizo en las Cortes de Alcalá de Henares en la era MCCCLXXXVI (año 1348,) Capítulo LXIIII, en Cortes de los antiguos reinos de León y de Castilla (Madrid, 1861), I, p. 541.

${ }^{81}$ Pérez-Victoria de Benavides, Manuel, Prelación de fuentes en Castilla (1348-1889). Granada, 1993, p. 18; MACDONALD, Robert A., Problemas politicos y derecho alfonsino considerados desde tres puntos de vista, en $A H D E ., 54$ (1989), pp. 32 ss.
} 
Por un lado, tanto la reivindicación del monopolio regio en la creación de derecho como el anhelo de unificación jurídica tropezaron con la oposición de amplios sectores de la sociedad política del reino, obligando al monarca a renunciar a algunos de sus propósitos en ambos sentidos. Por otra parte, ni el Espéculo ni las Partidas fueron promulgados durante su reinado, no adquiriendo fuerza legal en Castilla hasta mucho tiempo después, de forma que la renovación del contenido del derecho tuvo, de momento, un ámbito de aplicación restringido.

\section{BiBLIOGRAFÍA}

Alfonso Antón, María Isabel, Desheredamiento y desafuero, o la pretendida justificación de una revuelta nobiliaria, en Cahiers de linguistique et de civilisation hispaniques médiévales, 25 (2002), pp. 99-129.

Ayala Martínez, Carlos de, Directrices fundamentales de la política peninsular de Alfonso X: relaciones castellano-aragonesas de 1252 a 1263 (Madrid, Universidad Autónoma de Madrid, 1986).

-Alfonso X: Beaucaire y el fin de la pretensión imperial, en Hispania, 47 (1987), pp. 5-31.

BARRAGÁN, Guillermo C., La obra legislativa de Alfonso el Sabio: ensayo sobre su formación, promulgación y trascendencia americana (Buenos Aires, Abeledo-Perrot, 1983).

Barrero García, Ana María, El derecho romano en los Furs de Valencia de Jaime I, en AHDE., 41 (1971), pp. 639-664.

- El Fuero de Logroño, en SeSMA Muñoz, José Ángel (dir.), Historia de la ciudad de Logroño. II: Edad Media (Logroño, Ayuntamiento de Logroño, 1995), pp. 169-233.

Barrientos Grandón, Javier, La cultura jurídica en la Nueva España (México, Universidad Autónoma de México, Instituto de Investigaciones Jurídicas, 1993).

-El sistema del "ius commune" en las Indias occidentales, en Rivista internazionale di diritto comune, 10 (1999), pp. 53-138.

—Curso de Historia del Derecho (Santiago de Chile, Lexisnexis, 2004).

Berman, Harold Joseph, La formación de la tradición jurídica de Occidente (México, Fondo de Cultura Económica, 1996).

Bermejo Cabrero, José Luis, Fazañas e historiografia, en Hispania, 32 (1972), pp. 61-76.

- La idea medieval de contrafuero en León y Castilla, en Revista de Estudios Políticos, 187 (1973), pp. 299-306.

-Principios y apotegmas sobre la ley y el rey en la Baja Edad Media castellana, en Hispania, 129 (1975), pp. 31-47.

Bernal Gómez, Beatriz, Fueros, costums y otros textos de derecho español medieval, en Anuario Mexicano de Historia del Derecho, 2 (1990), pp. 313-317.

- El derecho castellano dentro del sistema jurídico indiano, en Anuario Mexicano de Historia del Derecho, 10 (1998), pp. 89-105.

- El derecho indiano, concepto, clasificación y características, en Ciencia Jurídica, 4 (2015), 7, pp. 183-193.

Borrero Fernández, Mercedes, Sevilla en la segunda mitad del siglo XIII. El nacimiento de sus instituciones de gobierno local, en Metropolis Totivs Hispaniae. Catálogo de la Exposición sobre el 750 Aniversario de la incorporación de Sevilla a la Corona de Castilla (Sevilla, Ayuntamiento de Sevilla, 1998), pp. 73-89. 
- El Concejo de Sevilla, en González Jiménez, Manuel; Borrero Fernández, Mercedes; Montes Romero-Camacho, Isabel, Sevilla en tiempos de Alfonso Xel Sabio (2a ed., Sevilla, Ayuntamiento de Sevilla, 2000), pp. 97-155.

Braga da Cruz, Guilherme, $O$ direito sudsidiário na história do direito português, en Revista Portuguesa de História, 14 (1975), pp. 177-316.

Bravo Lira, Bernardino, Formación del derecho occidental, con especial referencia a la Peninsula Ibérica (Santiago de Chile, Editorial Jurídica de Chile, 1970).

-El derecho indiano y sus raices europeas: derecho común y propio de Castilla, en AHDE., 58 (1988), pp. 5-80.

-Derecho común y derecho propio en el Nuevo Mundo (Santiago de Chile, Editorial Jurídica de Chile, 1989).

Calasso, Francesco, Medio Evo del diritto (Milano, Giuffrè, 1954).

Carpintero Benítez, Francisco, Mos italicus, mos gallicus y el humanismo racionalista. Una contribución a la historia de la metodología jurídica, en Ius Commune, 6 (1977), pp. 108-171.

Cavanna, Adriano, Storia del diritto moderno en Europa, I: Le fonti e il pensiero giuridico (Milano, Giuffrè, 1982).

CERDÁ RuIZ-FunES, Joaquín, Estudios sobre instituciones jurídicas medievales de Murcia y su reino (Murcia, Academia Alfonso X el Sabio, 1987).

Clavero Salvador, Bartolomé, Notas sobre el derecho territorial castellano (1367-1445), en Historia. Instituciones. Documentos, 3 (1976), pp. 141-166.

—Temas de historia del derecho: derecho de los reinos (Sevilla, Universidad de Sevilla, 1977).

—Temas de historia del derecho: derecho común (3a reimpr., Salamanca, Universidad de Salamanca, 1994).

Clavero Salvador, Bartolomé; Grossi, Paolo; Tomás y Valiente, Francisco, Hispania: entre derechos propios y derechos nacionales (Milano, Giuffrè, 1990).

Corng, Helmut, Derecho privado y europeo (Madrid, Fundación Cultural del Notariado, 1996).

Collantes de Terán SÁnchez, Antonio, El concejo de Sevilla en la Edad Media, en Ayuntamiento de Sevilla. Historia y Patrimonio. (Sevilla, Ayuntamiento de Sevilla, 1992), pp. 13-31.

CORTESE, Ennio, Il diritto nella storia medievale, II. Il baso medioevo (Roma, Il Cigno Galileo Galilei, 1995).

-Il rinascimiento giuridico medievale (Roma, Bulzoni, 1996).

CradDock, Jerry R., La cronología de las obras legislativas de Alfonso X el Sabio, en AHDE., 54 (1981), pp. 365-418.

-The Legislative Works of Alfonso X el Sabio: A Critical Bibliography (London, Grant \& Cutler, 1986).

-The Partidas: Bibliographical Notes, en Burns, Robert Ignatius (ed.), Las Siete Partidas. Volume One. The Medieval Church. The World of Clerics and Laymen (Philadelphia, University of Pennsylvania Press, 2001), pp. 41-48.

D’Abadal i Vinyals, Ramón, Les Partidas a Catalunya durant l'Edat Mitjana, en Estudis Universitaris Catalans, 4 (1912), pp. 159-180.

de Azevedo Ferreira, José Pedro (ed.), Alphonso X: Primeyra Partida (Braga, 1980).

Escalona Monge, Julio, Los nobles contra su rey. Argumentos y motivaciones de la insubordinación nobiliaria de 1272-1273, en Cahiers de linguistique et de civilisation hispaniques médiévales, 25 (2002), pp. 131-162. 
Estepa Díez, Carlos, Alfonso X y el fecho del Imperio, en Revista de Occidente, 43 (1984), pp. 43-54.

- El fecho del Imperio y la política internacional en la época de Alfonso X, en MONDÉJAR Cumpián, José (coord.), Estudios alfonsies: lexicografía, lírica, estética y política internacional en la época de Alfonso X (Granada, Universidad de Granada, 1985), pp. 189-205.

FonT Rius, Josep María, La recepción del derecho romano en la Península Ibérica durante la Edad Media (Montpellier, Faculté de Droit et des Sciences Économiques, 1967).

García Díaz, Jesús, El fenómeno del mercado en la obra legislativa de Alfonso Xel Sabio, en Historia. Instituciones. Documentos, 38 (2011), pp. 111-140.

- La Europa de Alfonso X el Sabio. En torno a una historia jurídica comparada, en Alcanate: Revista de Estudios Alfonsíes, 8 (2012-2013), pp. 263-290.

García-Gallo de Diego, Alfonso, Cuestiones de historiografía jurídica, II. La historia del derecho europeo, en AHDE., 44 (1974), pp. 751-764.

-Nuevas observaciones sobre la obra legislativa de Alfonso X, en AHDE., 46 (1976), pp. 609-670.

—La obra legislativa de Alfonso X. Hechos e hipótesis, en AHDE., 54 (1984), pp. 97-162.

- La problemática de la obra legislativa de Alfonso X, en Boletín del Ilustre Colegio de Abogados de Madrid, 5 (1984), pp. 8-19.

García-Pelayo, Manuel, Del mito y de la razón en la historia del pensamiento político (Madrid, Revista de Occidente, 1968).

GarCíA-SADELL, Luis María, Bibliografía sobre la obra jurídica de Alfonso el Sabio y su época (1800-1985), en Revista de la Facultad de Derecho. Universidad Complutense, 9 (1985), pp. 287-319.

García y García, Antonio, La penetración del derecho clásico en España, en AHDE., 36 (1966), pp. 575-592.

-Estudios sobre la canonistica portuguesa medieval (Madrid, Fundación Universitaria Española, 1976).

Gibert y SÁnchez de la Vega, Rafael, Elementos formativos del derecho en Europa: germánico, romano, canónico (Granada, Imprenta de Francisco Román, 1982).

-360 preguntas y respuestas sobre historia del derecho español, addenda para el curso primero en la Universidad Nacional a Distancia (Madrid, Universidad Nacional de Educación a Distancia, 1982).

Giménez y Martínez de Carvajal, José, El Decreto y Las Decretales, fuentes de la Primera Partida de Alfonso el Sabio, en Anthologica Annua, 2 (1954), pp. 239-248.

GonZÁlez ArCe, José Damián, Cuadernos de ordenanzas y otros documentos sevillanos de Alfonso X, en Historia. Instituciones. Documentos, 16 (1989), pp. 103-132.

GonzÁlez Díez, Emiliano, Del Fuero de la ciudad de Sevilla, en GonZÁlez JimÉnez, Manuel (dir.), Sevilla 1248. Congreso Internacional Conmemorativo del 750 Aniversario de la conquista de la ciudad de Sevilla por Fernando III, rey de Castilla y León (Sevilla, Ayuntamiento de Sevilla, 2000), pp. 279-302.

GonzÁlez JimÉnez, Manuel, Concejos y ciudades andaluzas: el gobierno urbano, en Concejos y ciudades en la Edad Media Hispánica: II Congreso de Estudios Medievales (Ávila, Fundación Sánchez-Albornoz, 1990), pp. 239-260.

- Alfonso X y las oligarquías urbanas de caballeros, en Glossae. Revista de Historia del Derecho Europeo, 5-6 (1993-1994), pp. 195-214. 
- Alfonso X, rey de Castilla y León (1252-1284), en Montoya MarTínez, Jesús; DoMÍNGUEZ RodríGUeZ, Ana (coords.), El scriptorium alfonsi: de los libros de astrología a las Cantigas de Santa Maria (Madrid, Editorial Universidad Complutense, 1999), pp. 1-16.

-Fernando III el Santo, legislador, en Minervae Baeticae. Boletín de la Real Academia Sevillana de Buenas Letras, 29 (2001), pp. 111-131.

- Sobre fueros, concejos y política municipal de Alfonso X, en Actas del II Congreso de Historia de Albacete: II: Edad Media (Albacete, Instituto de Estudios Albacetenses Don Juan Manuel, 2002), pp. 11-20.

-Alfonso X el Sabio (Barcelona, Ariel, 2004).

- La creación del derecho local y territorial andaluz. De Alfonso X a los Reyes Católicos, en Initium. Revista Catalana d'Història del Dret, 9 (2004), pp. 127-221.

González Mínguez, César, La concesión del Fuero Real a Vitoria, en Historia. Instituciones. Documentos, 28 (2001), pp. 217-229.

Grossi, Paolo, El orden jurídico medieval (Madrid, Marcial Pons, 1996).

Guilarte Zapatero, Alfonso, Castilla, país sin leyes (Valladolid, Ámbito, 1989).

Hespanha, António Manuel; Serrano González, Manuel (eds.), Cultura jurídica europea: sintesis de un milenio (Madrid, Tecnos, 2002).

Iglesia Ferreirós, Aquilino, Las Cortes de Zamora de 1274 y los casos de corte, en AHDE., 41 (1971), pp. 953-957.

-Derecho municipal, derecho señorial, derecho regio, en Historia. Instituciones. Documentos, 4 (1977), pp. 115-197.

- La creación del derecho en Cataluña, en AHDE., 47 (1977), pp. 99-423.

- ¿El primer testimonio de la recepción del derecho romano en Cataluña?, en Revista Jurídica de Cataluña, 79 (1978), pp. 277-231.

-Alfonso Xy su obra legislativa: algunas reflexiones, en AHDE., 50 (1980), pp. 531-562.

- Alfonso X, su labor legislativa y los historiadores, en Historia. Instituciones. Documentos, 9 (1982), pp. 2-112.

—Fuero Real y Espéculo, en AHDE., 52 (1982), pp. 111-191.

- La labor legislativa de Alfonso X el Sabio, en Pérez MarTín, Antonio (ed.), España y Europa, un pasado jurídico común. Actas del I Simposio Internacional del Instituto de Derecho Común (Murcia, Instituto de Derecho Común, 1986), pp. 275-599.

- Una traducción catalana de la Segunda Partida, en Anuario de Estudios Medievales, 17 (1987), pp. 265-278.

- Derecho municipaly derecho territorial en la Corona de Castilla, en El Fuero de Santander y su época: Actas del Congreso Conmemorativo de su VIII Centenario (Santander, Ediciones de Librería Estudio, 1989), pp. 115-151.

-(ed. lit.), Tercer Simposi Internacional del Dret Comú $i$ Catalunya: ius propium-ius commune a Europa (Barcelona, Pagès editors, 1993).

- La creación del derecho: una historia de la formación de un derecho estatal español (Madrid, Marcial Pons, 1996).

- La forja de la civilización europea: el ius commune, en García Marín, José María (dir.), Cultura jurídica europea: una herencia persistente (Sevilla, Universidad Pablo de Olavide, 2001), pp. 39-60.

-Por que nos, don Alfonso, avemos poder de fazer leyes, en Alcanate: Revista de Estudios Alfonsies, 3 (2002-2003), pp. 55-92.

ITURMENDi Morales, José, En torno a la idea de Imperio en Alfonso Xel Sabio, en Revista de Estudios Políticos, 182 (1972), pp. 88-155. 
Kantorowicz, Ernst H., Los dos cuerpos del rey. Un estudio de teología política medieval (Madrid, Akal, 2012).

Kern, Fritz, Derecho y constitución en la Edad Media (Valencia, Kyrios, 2013).

KirSCHBERG SCHENCK, Deborah, La reforma municipal en Sevilla: oligarquia hispalense y la implantación del regimiento en 1286, en Archivo Hispalense, 237 (1995), pp. $11-40$.

Kirschberg Schenck, Deborah; Fernández Gómez, Marcos, El Concejo de Sevilla en la Edad Media (1248-1454). Organización institucional y fuentes documentales (Sevilla, Ayuntamiento de Sevilla, 2002).

KLEINE, Marina, Os elementos do corpo politico e a justiça nas Siete Partidas de Alfonso X (1221-1284), en Politeia: Hist. e Soc., 5/1 (2005), pp. 103-118.

KorschaKer, Paul, Europa y el derecho romano (Madrid, Revista de Derecho Privado, 1955).

Lacarra y De Miguel, José María, En torno a la formación del Fuero General de Navarra, en $A H D E$., 50 (1980), pp. 93-110.

LaLINDE ABADÍA, Jesús, Iniciación histórica al derecho español (4a ed., Barcelona, PPU, 1989).

-El modelo jurídico europeo del siglo XIII, en Glossae: Revista de Historia del Derecho Europeo, 5-6 (1993-1994), pp. 17-34.

MacDonald, Robert A., Problemas políticos y derecho alfonsino considerados desde tres puntos de vista, en AHDE., 54 (1989), pp. 25-53.

-Derecho y política: el programa de reforma política de Alfonso X, en BURNs, Robert Ignatius (comp.), Los mundos de Alfonso el Sabio y Jaime el Conquistador. Razón y fuerza en la Edad Media (Valencia, Institució Valenciana d'Estudis i Investigació, 1990), pp. 179-232.

Madero Eguía, Marta, Formas de la justicia en la obra jurídica de Alfonso X el Sabio, en Hispania, 66/2 (1996), pp. 447-466.

Marongiu, Antonio, Un momento típico de la monarquía medieval: el rey juez, en AHDE., 23 (1953), pp. 677-715.

Martínez Díez, Gonzalo, Poblamiento y ordenamiento jurídico en el País Vasco. El estatuto jurídico de la población rural y urbana, en Las formas del poblamiento en el señorio de Vizcaya durante la Edad Media (Bilbao, Diputación Provincial de Vizcaya, 1978), pp. 129-169.

Martínez Díez, Gonzalo, Los comienzos de la recepción del derecho romano en España y el Fuero Real, en Diritto comune e diritti locali nella storia dell'Europa. Atti del Convegno di Varenna (Milano, Giuffrè, 1980), pp. 253-262.

—(ed.), Leyes de Alfonso X, I: Espéculo (Ávila, Fundación Sánchez-Albornoz, 1985).

-(ed.), Leyes de Alfonso X, II: Fuero Real (Ávila, Fundación Sánchez-Albornoz, 1988).

Montanos Ferrín Emma, Experiencias de derecho común europeo: siglos XII-XVII (Santiago de Compostela, Andavira Editora, 2010).

Nieto Soria, José Manuel, Fundamentos ideológicos del poder real en Castilla (siglos XIII-XVI) (Madrid, Eudema, 1988).

O'Callaghan, Joseph F., Sobre la promulgación del Espéculo y del Fuero Real, en Estudios en homenaje a don Claudio Sánchez Albornoz en sus 90 cumpleaños. Anexos de Cuadernos de Historia de España (Buenos Aires, Instituto de España, 1985), pp. 178-179.

_El rey Sabio. El reinado de Alfonso X de Castilla (Sevilla, Universidad de Sevilla, 1999). 
Peinado Santaella, Rafael Gerardo, Las élites de poder en las ciudades de la Andalucía Bética, en Las ciudades andaluzas (Siglos XIII-XVI). Actas del VI Coloquio Internacional de Historia Medieval de Andalucía (Málaga, Universidad de Málaga, 1991), pp. 337-356.

PÉrez de la CANAL, Miguel Ángel, La justicia en la corte de Castilla durante los siglos XIII al XIV, en Historia. Instituciones. Documentos, 2 (1975), pp. 385-471.

Pérez de Tudela y Velasco, María Isabel, Ideario político y orden social en Las Partidas de Alfonso X, en En la España Medieval, 14 (1991), pp. 183-200.

Pérez Martín, Antonio, El estudio de la recepción del derecho común en España, en Salvador Coderch, Pablo; Cerdá Ruiz-Funes, Joaquín (coords.), I Seminario de historia del derecho y derecho privado: nuevas técnicas de investigación (Barcelona, Universitat Autònoma de Barcelona, 1985), pp. 241-325.

-Murcia y la obra legislativa alfonsina: pasado y presente, en Anales de la Universidad de Murcia, 8 (1985), pp. 105-107.

-Jacobo de las Leyes: datos biográficos, en Glossae: Revista de Historia del Derecho Europeo, 5-6 (1994), pp. 279-332.

- Hacia un derecho común europeo: la obra jurídica de Alfonso X, en Rodríguez LLOPIS, Manuel (coord.), Alfonso X. Aportaciones de un rey castellano a la construcción de Europa (Murcia, Consejería de Cultura y Educación, 1997), pp. 109-134.

- Las Siete Partidas, obra cumbre del derecho común en España, en GARCía y García, Antonio et alii, El derecho común y Europa. Actas de las Jornadas Internacionales de Historia de El Escorial (Madrid, Dykinson, 2000), pp. 21-34.

-(coord.), España y Europa: un pasado jurídico común. Actas del I Simposio Internacional del Instituto de Derecho Común (Murcia, Instituto de Derecho Común, 1986).

Pérez-Prendes y Muñoz de Arracó, José Manuel, Facer justicia, en Moneda y Crédito, 129 (1974), pp. 17-90.

—Las leyes de Alfonso el Sabio, en Revista de Occidente, 43 (1984), pp. 67-84.

- La obra jurídica de Alfonso X, en Alfonso X. Catálogo de la Exposición de Toledo, 1984 (Madrid, Ministerio de Cultura, 1984), pp. 49-62.

Pérez-Victoria de Benavides, Manuel, Prelación de fuentes en Castilla (1348-1889) (Granada, Universidad de Granada, 1993).

PIÑa Homs, Román, Alfonso X el Sabio: Universalidad frente a localismo, en Alvarado Planas, Javier (coord.), Espacios y fueros en Castilla-La Mancha (Siglos XI-XVI). Una perspectiva metodológica (Madrid, Polifemo, 1995), pp. 471-486.

Procter, Evelyn S., Alfonso X de Castilla, patrono de las letras y del saber (Murcia, Academia Alfonso X el Sabio, 2002).

Prodi, Paolo, Una storia della giustizia: dal pluralismo dei fori al moderno dualismo tra coscienza e diritto (Bologna, Il Mulino, 2000).

Ruiz de la Peña Soler, José Ignacio, La expansión del Fuero de Benavente, en Archivos Leoneses, 24 (1970), pp. 299-307.

-Poblamiento y cartas pueblas de Alfonso X y Sancho IV en Galicia, en Homenaje a don José $M^{a}$ Lacarra en su jubilación del profesorado. Estudios Medievales (Zaragoza, Anubar, 1977), pp. 27-60.

-Las "polas" asturianas en la Edad Media. Estudio y Diplomatario (Oviedo, Universidad de Oviedo, 1981). 
Sánchez-Arcilla Bernal, José, La obra legislativa de Alfonso Xel Sabio. Historia de una polémica, en Montoya Martínez, Jesús; Domínguez Rodríguez, Ana (coords.), El scriptorium alfonsi: de los libros de astrología a las Cantigas de Santa María (Madrid, Editorial Universidad Complutense, 1999), pp. 17-81.

- La teoría de la ley en la obra legislativa de Alfonso X el Sabio, en Alcanate: Revista de Estudios Alfonsies, 6 (2008-2009), pp. 81-123.

SÁnCHEZ CASADO, Galo, Para la historia de la redacción del antiguo derecho territorial, en $A H D E$., 6 (1929), pp. 260-328.

Suárez Bilbao, Fernando; Navalpotro y Sánchez-Peinado, Jesús María, La consolidación del derecho común en Castilla. La obra legislativa de los Reyes Católicos, en Le droit commun et l'Europe. Journées Internationales d'Histoire du Droit de L'Escurial (Madrid, Dykinson, 2000), pp. 285-314.

Tomás y Valiente, Francisco, Manual de historia del derecho español (3a ed., Madrid, Tecnos, 1981).

Torres Fontes, Juan, Murcia y Las Partidas, en AHDE., 34 (1954), pp. 531-545.

-Documentos de Alfonso X el Sabio. Colección de Documentos para la Historia del Reino de Murcia (Murcia, Academia Alfonso X el Sabio, 1963).

-Fueros y privilegios de Alfonso X al reino de Murcia (Murcia, Academia Alfonso X el Sabio, 1973).

Ullmann, Walter, Principios de gobierno y política en la Edad Media (Barcelona, Ariel, 1992).

Vallejo Fernández De La Reguera, Jesús, Ruda equidad, ley consumada. Concepción de la potestad normativa (1250-1350) (Madrid, Centro de Estudios Constitucionales, 1992).

- Relectura del Fuero Real, en Romano, Andrea (a cura di), Federico II legislatore del Regno di Sicilia nell'Europa del Duecento. Per una storia comparata delle codificazioni europee (Roma, Edizioni de Luca, 1997), pp. 485-514.

Wolf, Armin, Los "Fori Aragonum" de 1247 y el "Vidal Mayor". Sus relaciones con la legislación europea, en AHDE., 53 (1983-1984), pp. 177-203.

-Derecho electivo y sucesión hereditaria en los reinos y en el Imperio de Alfonso el Sabio, en Pérez Martín, Antonio (ed.), España y Europa: un pasado jurídico común. Actas del I Simposio Internacional del Instituto de Derecho Común (Murcia, Instituto de Derecho Común, 1986), pp. 223-257.

-El movimiento de legislación y de codificación en Europa en tiempos de Alfonso X el Sabio, en Miguel Rodríguez, Juan Carlos de; Muñoz FernÁndeZ, Ángela; Segura Graíño, Cristina (eds.), Alfonso X el Sabio, vida obra y época (Madrid, Sociedad Española de Estudios Medievales, 1989), pp. 31-37. 